\title{
Ignition and Chemical Kinetics of Acrolein-Oxygen-Argon Mixtures Behind Reflected Shock Waves
}

\author{
K. Chatelain ${ }^{\mathrm{a}}$, R. Mével ${ }^{*, a}$, S. Menon ${ }^{\mathrm{b}}$, G. Blanquart ${ }^{\mathrm{b}}$, J.E. Shepherd ${ }^{\mathrm{a}}$ \\ ${ }^{a}$ Graduate Aerospace Laboratories, California Institute of Technology, \\ 1200 E. California Blvd, Pasadena, California 91125, USA \\ ${ }^{b}$ Department of Mechanical and Civil Engineering, California Institute of Technology, \\ 1200 E. California Blvd, Pasadena, California 91125, USA
}

\begin{abstract}
In order to address increasing greenhouse gas emissions, the future fossil fuel shortage and increasingly stringent pollutant emission regulations, a variety of biofuels are being progressively incorporated into conventional transportation fuels. Despite the beneficial impact of biofuels on most regulated pollutants, their combustion induces the increase of a variety of aldehydes that are being considered for specific regulations due to their high toxicity. One of the most hazardous aldehyde compounds is acrolein, $\mathrm{C}_{2} \mathrm{H}_{3} \mathrm{CHO}$. Despite its high toxicity and increased formation during bioalcohol and biodiesel combustion, no experimental data are available for acrolein combustion. In the present study, we have investigated the ignition of acrolein-oxygen-argon mixtures behind reflected shock wave using three simultaneous emission diagnostics monitoring $\mathrm{OH}^{*}, \mathrm{CH}^{*}$ and $\mathrm{CO}_{2}{ }^{*}$. Experiments were performed over a range of conditions: $\Phi=0.5-2 ; \mathrm{T}_{5}=1178-1602 \mathrm{~K}$; and $\mathrm{P}_{5}=173-416$ $\mathrm{kPa}$. A tentative detailed reaction model, which includes sub-mechanisms for the three measured excited species, was developed to describe the high-temperature chemical kinetics of acrolein oxidation. Reasonable agreement was found between the model prediction and experimental data.
\end{abstract}

Key words: Biofuel, Acrolein, Toxic pollutant, Ignition delay-time, High-temperature chemical kinetics

\footnotetext{
${ }^{*}$ Corresponding author: mevel@caltech.edu
} 


\section{Introduction}

In recent years, biofuels have received growing attention as an alternative to petroleum-based fuels in light of increasing greenhouse gas emissions, supply shortages and stringent regulations on pollutant emissions [1, 2, 3, 4]. Depending on the specific biofuel considered, significant reduction in carbon dioxide emission has been reported $[3,4]$. Despite the positive impact in reducing pollutant emissions, like particulate matter $[3,5,6], \mathrm{CO}[3,5]$, and unburnt hydrocarbons $[3,5]$, by incorporating biofuels into conventional fuels, their combustion generates an increase production of a variety of toxic carbonyl compounds, especially aldehydes $[2,7,8,9]$. This concern is aggravated by new engine combustion technologies such as homogeneous charge compression ignition and premixed charge compression ignition which involve low-temperature reaction kinetics [8]. Studies $[5,6,10]$ have demonstrated acrolein production is increased up to $1000 \%$ for diesel-ethanol and diesel-biodiesel blends [6]. Acrolein or 2-propenal, $\mathrm{C}_{2} \mathrm{H}_{3} \mathrm{CHO}$, is a beta-unsaturated aldehyde with important implications for atmospheric chemistry [11]. High levels of acrolein have been correlated with urban areas having dense automotive traffic as well as rural areas subject to forest fires [12]. In addition to its formation during combustion processes, including burning of fossil fuels [13]; wood; plastic; and tobacco [12], acrolein can be formed in the atmosphere as a result of chemical reactions involving unsaturated hydrocarbons like 1,3-butadiene [14]. Although no conclusive carcinogenic evidence has been found for acrolein, its increased production during the combustion of biofuels is particularly concerning for public heath due to its neurotoxic properties [11]. Acrolein is highly toxic and physiological effects can potentially occur through inhalation or skin exposure for concentrations as low as $0.3 \mathrm{ppm}$ [12].

Given the expected growing use of biofuels and the physiological implications of acrolein, a better understanding of its chemical kinetics is of importance. While acrolein chemistry is incorporated into a number of chemical reaction models of hydrocarbon fuels, most studies have focused on its reactivity at low temperature in the framework of atmospheric chemistry, see [11]. The objective of the present work is to gain insight into the high-temperature acrolein kinetics independently of the complexity involved in the study of heavy hydrocarbon fuels. To this end, 
the chemical kinetics of acrolein has been studied behind reflected shock wave by monitoring simultaneously the emission from $\mathrm{OH}^{*}, \mathrm{CH}^{*}$ and $\mathrm{CO}_{2}{ }^{*}$. A tentative detailed reaction mechanism, which includes sub-mechanisms for the three measured excited species, has been developed and analyzed to underline the dominant reaction pathways.

\section{Materials and methods}

\subsection{Mixtures preparation}

All gases were of research grade (Air Liquide). A mixture containing $2 \%$ by volume of acrolein in argon was used to prepare the blends. Because of the highly toxic and corrosive properties of acrolein, special materials and procedures were employed. Corrosion-resistant regulator and pipe-lines were used. Special care was taken to minimize leaks. Integral gas-mask, protection gloves and laboratory coat were used during mixture preparation and experiment. Homogeneity of the mixtures was obtained by active mixing for one hour. Mixture compositions and experimental conditions are summarized in Table 1.

\subsection{Experimental apparatus}

The shock-tube used has been described elsewhere $[15,16]$. It is composed of three parts separated by two diaphragms and is made of stainless steel. The driver section and the driven section are 6.19- and 11.28-m-long, respectively, (i.d. 15.24 $\mathrm{cm}$ ). The test section is 2.44-m-long (i.d. $7.62 \mathrm{~cm}$ ). A 2.03-m-long (i.d. 7.62 $\mathrm{cm})$ cookie-cutter is used to transmit the shock wave from the driven to the test section, avoiding perturbation of the incident shock wave. The residual vacuum in the test section is on the order of $1 \mathrm{~Pa}$. The driver gas was nitrogen. The test section of the shock-tube was equipped with diagnostic instruments located close to the end wall: four piezoelectric pressure transducers, mounted flush with the inside wall for shock velocity measurements (uncertainty of 1\%), and two quartz optical windows mounted at $10 \mathrm{~mm}$ from the tube end, connected to two solarizationresistant multimode optical fibers with a core diameter of $200 \mu \mathrm{m}$. One of the optical fiber is linked to a single-photomultiplier (Hamamatsu) equipped with a $306 \pm 5 \mathrm{~nm}$ 
band-pass filter for detecting the $\left(\mathrm{A}^{2} \Sigma^{+}-\mathrm{X}^{2} \Pi\right)$ transition of excited $\mathrm{OH}$ radicals, $\mathrm{OH}^{*}$. The second fiber is linked to a dual-photomultiplier (Thorlabs) equipped with a quartz beam splitter and two band-pass filters centered at $410 \pm 5 \mathrm{~nm}$ and $430 \pm 5$ $\mathrm{nm}$ for detecting the $\left(\mathrm{A}^{1} \mathrm{~B}^{2}-\mathrm{X}^{1} \Sigma^{+}\right)$and $\left(\mathrm{A}^{2} \Delta-\mathrm{X}^{2} \Pi\right)$ transitions of $\mathrm{CO}_{2}{ }^{*}$ and $\mathrm{CH}^{*}$ radicals, respectively. Characteristic times of reaction were defined as the time to reach $50 \%$ and $100 \%$ of the emission peak, $\tau_{50 \%}$ and $\tau_{100 \%}$ respectively. The setups of the photomultipliers were held constant to obtain normalized peak heights as a function of temperature. Note that the series performed for the stoichiometric mixture was employed to evaluate the sensitivity of the new dual-photomultiplier as well as the emission characteristics of acrolein-based mixtures. These mixtures demonstrated sensibly different emission intensities than mixtures previously studied in our laboratory $[15,16]$. These aspects resulted in missing parameters as seen in Table 2 to Table 4 which summarize all the results obtained. The thermodynamic conditions behind the reflected shock wave were calculated using the $1 \mathrm{D}$ shock theory and the incident shock velocity. Uncertainties on the reflected temperature and pressure are 1\%. Uncertainties on the delay-time and the peak height is on the order of $20 \%$. Figure 1 shows a typical example of $\mathrm{OH}^{*}$ emission and pressure signals obtained during the present study.

\subsection{Chemical kinetic scheme}

The detailed reaction model presently used includes 920 reactions and 115 species. It was developed from the model of Mével et al. [17, 18] for $\mathrm{H}_{2}-\mathrm{O}_{2}$ and $\mathrm{NO}_{x}$ chemistry, the Caltech mechanism [19] for hydrocarbon chemistry and the model of Le Cong for $\mathrm{NO}_{x}$-hydrocarbons interactions [20]. The sub-model for acrolein chemistry was taken from the Jet-Surf model [21] and extended based on an analogy with 1,3-butadiene chemistry. Sub-mechanisms for $\mathrm{OH}^{*}, \mathrm{CH}^{*}$ and $\mathrm{CO}_{2} *$ chemistry were respectively taken from Hall et al. [22, 23] and Hidaka et al. [24, 25]; Devriendt et al. [26] and Smith et al. [27]; and Kopp et al. [28] and Sulzmann et al. [29]. The JetSurf mechanism [21] was also employed for comparison with the present reaction model. Missing thermodynamic properties for acrolein and acrolein radicals, $\mathrm{C}_{2} \mathrm{H}_{3} \mathrm{CO}$, CHCHCHO, $\mathrm{CH}_{2} \mathrm{CCHO}$, were calculated following the methodology 
outlined in [30]. The model is provided as a supplemental material along with the corresponding thermodynamic properties. The modeling of the experimental results was performed with SENKIN [31] using the constant volume reactor model. Sensitivity and reaction pathway analyses were performed using this code.

The performance of the two reaction mechanisms were quantified using the mean and the maximum errors, respectively defined as

$$
E_{\text {mean }}^{Q}=\frac{1}{N} \sum_{i}^{N}\left|\frac{\Delta Q}{Q_{\text {expe }}}\right|
$$

and

$$
E_{\max }^{Q}=\max \left|\frac{\Delta Q}{Q_{\text {expe }}}\right| .
$$

$\mathrm{N}$ is the number of data points, $\Delta Q=Q_{\text {model }}-Q_{\text {expe }}$, with $Q_{\text {model }}$ and $Q_{\text {expe }}$ are the calculated and experimental characteristic quantities, respectively. The characteristic quantities refer to the delay-times, $\tau_{50 \%}$ and $\tau_{100 \%}$, and the normalized peak heights. The absolute values are used to avoid positive and negative contributions to the errors canceling out.

\section{Results and discussion}

\subsection{Experimental results}

The ignition delay-times based on $\mathrm{OH}^{*} ; \mathrm{CH}^{*}$; and $\mathrm{CO}_{2}{ }^{*}$ of acrolein-oxygenargon mixtures were measured behind reflected shock wave in the ranges: $\Phi=0.5-2$; $\mathrm{T}_{5}=1178-1602 \mathrm{~K}$; and $\mathrm{P}_{5}=173-416 \mathrm{kPa}$. Within the experimental uncertainty, the three species monitored yield similar values for the ignition delay-time. Figure 2 to Figure 4 display the results obtained for a lean, a stoichiometric and a rich mixture, respectively. For the three monitored emissions, the delay-times increase with the equivalence ratio. For example, at a temperature of $1400 \mathrm{~K}, \tau_{50 \%}$ based on $\mathrm{OH}^{*}$ is twice shorter for the lean, $\Phi=0.5$, than for the rich, $\Phi=2$, mixture. Performing a multi-linear fitting without constraint on $\tau_{50 \%}$ measured for $\mathrm{OH}^{*}$, the experimental results can be approximated within $\pm 13 \%$ by the following expression:

$$
\tau_{50 \%}(O H *)=1.45136 .10^{-06}\left[C_{2} H_{3} C H O\right]^{0.257}\left[O_{2}\right]^{-0.774}[A r]^{-0.014} \exp \left(\frac{126194}{R T}\right),
$$


where: $\mathrm{A}=1.45136 .10^{-06}$ is the pre-exponential factor $(\mu \mathrm{s}) ; \mathrm{Ea}=126194$ is the activation energy $(\mathrm{J} / \mathrm{mol})$; $\mathrm{R}$ is the universal gas constant $\left(\mathrm{J} . \mathrm{K}^{-1} \cdot \mathrm{mol}^{-1}\right)$; and $\mathrm{T}$ is the temperature $(\mathrm{K})$.

Figure 5 compares the normalized $\tau_{50 \%}\left(\mathrm{OH}^{*}\right)$ for acrolein-oxygen-argon mixtures obtained experimentally and predicted from the above empirical correlation (Equation 3). The exponents on the fuel and oxygen concentration are consistent with previous results obtained for small alkanes [32], large alkanes [33, 34], alkenes [35], and aldehydes $[2,7]$. An increase of $\left[\mathrm{O}_{2}\right]$ favors $\mathrm{OH}$ radical production through the branching reaction $\mathrm{H}+\mathrm{O}_{2}=\mathrm{OH}+\mathrm{O}$ whereas the increase of [Fuel] induces a consumption of $\mathrm{H}$ atoms through Fuel $+\mathrm{H}=\mathrm{Alkyl}+\mathrm{H}_{2}$. The activation energy, $126 \mathrm{~kJ} / \mathrm{mol}$, is lower than activation energies reported for n-butanal (another aldehyde with an alkyl chain instead of an alkenyl chain) by Zhang et al. [2], $166 \mathrm{~kJ} / \mathrm{mol}$, and Davidson et al. [7], $180 \mathrm{~kJ} / \mathrm{mol}$. The measured activation energy of acrolein is closest to that reported for ethylene by Kalitan et al. [35], $111 \mathrm{~kJ} / \mathrm{mol}$, and Horning [36], interpolated value at $300 \mathrm{kPa}$ is $137 \mathrm{~kJ} / \mathrm{mol}$. The activation energy reported for $1,3-$ butadiene-oxygen-argon mixtures, based on time to half-maximum $\mathrm{OH}$ absorption, is $149 \mathrm{~kJ} / \mathrm{mol}$ [37]. These results seem to indicate that the nature of the hydrocarbon linear chain, saturated or unsaturated, dominate the ignition process over the presence of the aldehyde function. This is consistent with previous observations by Davidson et al. [7].

Figure 6 shows typical examples of emission profiles for $\mathrm{CO}_{2}{ }^{*}, \mathrm{OH}^{*}$ and $\mathrm{CH}^{*}$. For the rich mixture, emission prior to ignition was observed for $\mathrm{OH}^{*}$ and $\mathrm{CO}_{2}{ }^{*}$ as seen in Figure 6. The intensity of the emission prior to ignition is higher for $\mathrm{CO}_{2}{ }^{*}, 10 \%$ of the main peak, than for $\mathrm{OH}^{*}, 5 \%$ of the main peak. This feature was not observed for $\mathrm{CH}^{*}$. Overall, the profiles for $\mathrm{CH}^{*}$ emission appear thinner than for $\mathrm{CO}_{2}{ }^{*}$ emission. For $\mathrm{OH}^{*}$, the emission decreases rapidly after the maximum is reached and then decreases more slowly to form a trailing feature. Figure 7 and Figure 8 display the evolution of normalized emission peak as a function of temperature. To normalize the peak height, we maintained a constant set-up (voltage) of the PMTs and we used the highest peak height (obtained at the highest temperature) to normalize the peak heights obtained at lower temperatures. Consistent with previous results from 
Kopp et al. for $\mathrm{CO}_{2}{ }^{*}[28]$, the peak height increases with temperature for all three emissions. This trend can be explained using a quasi-steady-state analysis similar to that from Mével et al. [15]. Details are given in the next section.

\subsection{Modeling results}

\subsubsection{Delay-times and emission profiles}

Figure 2 to Figure 4 present a comparison between the experimental delay-times and the predictions from the present reaction model and from the JetSurf mechanism. The data are fairly well reproduced for the fuel-lean mixture. For the stoichiometric mixture, the delay-times are slightly under-estimated but the activation energy is well matched. For the fuel-rich mixture, the activation energy is slightly over-estimated. The mean errors on the delay-times are $26 \%, 22 \%$, and $19 \%$ for $\mathrm{OH}^{*}, \mathrm{CH}^{*}$, and $\mathrm{CO}_{2}{ }^{*}$, respectively. Note that Figure 2 to Figure 4 display the predictions obtained using the correlation from Slack and Grillo [38] for $\mathrm{CO}_{2}{ }^{*}$, see comments below. The largest discrepancies are observed for $\mathrm{OH}^{*}$ in the rich mixture but the predictions remain within $70 \%$ of the experimental values. In order to achieve this agreement, four rate constants were modified for:

$-\mathrm{R}_{1}: \mathrm{C}_{2} \mathrm{H}_{3} \mathrm{CHO}=\mathrm{C}_{2} \mathrm{H}_{3}+\mathrm{HCO}$ :

$$
\begin{aligned}
& \mathrm{k}_{1}^{P S}=2.48 .10^{24} \mathrm{~T}^{-2.153} \exp (-427054 / R T) ; \\
& \mathrm{k}_{1}^{J S}=2.48 .10^{24} \mathrm{~T}^{-2.153} \exp (-418680 / R T)
\end{aligned}
$$

$-\mathrm{R}_{2}: \mathrm{C}_{2} \mathrm{H}_{3} \mathrm{CHO}+\mathrm{O}=\mathrm{C}_{2} \mathrm{H}_{3}+\mathrm{OH}+\mathrm{CO}:$

$$
\begin{aligned}
& \mathrm{k}_{2}^{P S}=3.00 .10^{13} \exp (-20934 / R T) ; \mathrm{k}_{2}^{J S}=3.00 .10^{13} \exp (-14821 / R T) \\
& -\mathrm{R}_{3}: \mathrm{C}_{2} \mathrm{H}_{3} \mathrm{CHO}+\mathrm{OH}=\mathrm{C}_{2} \mathrm{H}_{3}+\mathrm{H}_{2} \mathrm{O}+\mathrm{CO}: \\
& \mathrm{k}_{3}^{P S}=3.49 .10^{09} \mathrm{~T}^{1.1} \exp (1871 / R T) ; \mathrm{k}_{3}^{J S}=3.49 .10^{09} \mathrm{~T}^{1.18} \exp (1871 / R T) \\
& -\mathrm{R}_{4}: \mathrm{C}_{2} \mathrm{H}_{3} \mathrm{CHO}+\mathrm{O}=\mathrm{CH}_{2} \mathrm{O}+\mathrm{CH}_{2} \mathrm{CO}: \\
& \mathrm{k}_{4}^{P S}=3.17 .10^{14} \exp (-40704 / R T) ; \mathrm{k}_{4}^{J S}=1.9 .10^{7} \mathrm{~T}^{1.8} \exp (-921 / R T)
\end{aligned}
$$

where $\mathrm{k}_{i}^{P S}$ and $\mathrm{k}_{i}^{J S}$ refer to the rate constant used in the present study and in JetSurf, respectively. 
The modified rate constants remain within a factor of two in the temperature range presently studied as compared to the values proposed in JetSurf [21]. Such modifications are consistent with typical accuracy of theoretical calculations of rate constants [39]. The JetSurf values were based on the recommendation from Tsang and Hampson [40] for the reverse reaction of $R_{1}$ and on analogies with formaldehyde for $R_{2}$ and $\mathrm{R}_{3}$, and with $\mathrm{C}_{2} \mathrm{H}_{4}$ for $\mathrm{R}_{4}$. The mean error on the experimental data observed when using the JetSurf was on the order of $25-40 \%$ depending on the emission considered, with a maximum error close to $80 \%$. Overall, the JetSurf tends to under-predict the delay-times.

As an alternative to solving for the excited state of $\mathrm{CO}_{2}$ directly in the chemical model, the profiles of $\mathrm{CO}_{2}{ }^{*}$ were calculated using the expression proposed by Slack and Grillo [38]:

$$
\left[\mathrm{CO}_{2} *\right] \approx 6.8 .10^{5}[\mathrm{CO}][O] \exp \left(\frac{-16295}{R T}\right),
$$

where the pre-exponential factor is expressed in $\mathrm{cm}^{3} / \mathrm{mol} \mathrm{s}$, and the activation energy in $\mathrm{J} / \mathrm{mol}$.

This expression reproduces the delay-times based on $\mathrm{CO}_{2}{ }^{*}$ emission better than the detailed reaction model assembled from Kopp et al. [28] and Sulzmann et al. [29] studies. Kopp et al. stated that their reaction model for $\mathrm{CO}_{2}{ }^{*}$ was tentative. For instance, they used the rate constants proposed for the ground state $\mathrm{CO}_{2}$ to describe the formation of $\mathrm{CO}_{2}{ }^{*}$. These values were disregarded in the present study and the formation of $\mathrm{CO}_{2}{ }^{*}$ was assumed to be due only to the reaction $\mathrm{CO}+\mathrm{O}+\mathrm{M}=\mathrm{CO}_{2}{ }^{*}+\mathrm{M}$ and the rate constant was taken from Sulzmann et al. [29]. To describe the quenching of $\mathrm{CO}_{2}{ }^{*}$, Kopp et al. assumed that the rate constants were the same as those for the quenching of $\mathrm{OH}^{*}$. From elementary collision theory, it can be argued that the effective collision section of $\mathrm{CO}_{2}{ }^{*}$ should be larger than that of $\mathrm{OH}^{*}$ and consequently, the rate constants should be higher. We did not attempt to propose an updated reaction model for the chemistry of $\mathrm{CO}_{2}{ }^{*}$ because our experiments are not well suited for this purpose. The kinetics of acrolein is complex and involves a number of chemical steps that are not well characterized. Because the dynamics of an excited species is highly dependent on the ground state chemistry [17, 41, 42], simpler and better-known chemical systems such as carbon monoxide- or methane- 
based mixtures should be employed for such reaction rate determination.

The discrepancies of the $\mathrm{CO}_{2}{ }^{*}$ sub-model are also reflected in the predicted normalized profile of Figure 6. Both models over-estimate the intensity of the emission prior to ignition whereas the correlation from Slack and Grillo [38] reproduces fairly well the whole profile. As shown in Figure 8, the correlation reproduces reasonably well the variation of the emission peak height with temperature. A pathway analysis indicates that the rate constant of the quenching reaction by argon is probably too low. For $\mathrm{OH}^{*}$, the normalized emission profiles are overall well reproduced by the present model as illustrated in Figure 6. The JetSurf tends to predict too wide emission peaks and does not capture the trailing feature which follows the fast decrease of the emission signal. The main emission event is due to $\mathrm{CH}+\mathrm{O}_{2}=\mathrm{OH}^{*}+\mathrm{CO}$ whereas the trailing feature relates to $\mathrm{H}+\mathrm{O}+\mathrm{M}=\mathrm{OH}^{*}+\mathrm{M}$. The evolution of the peak height with temperature is well predicted for the lean mixture, Figure 7, but is underestimated for the rich mixture, Figure 8. Both models demonstrate similar trends. Concerning $\mathrm{CH}^{*}$, the calculated emission profiles are overall too narrow as compared to experiments. This difference might be explained by the contribution of the broadband emission of $\mathrm{CO}_{2}{ }^{*}$ at $430 \mathrm{~nm}$ as illustrated in [28]. The possible influence of the chemiluminescence from $\mathrm{CO}_{2}{ }^{*}$ has previously been emphasized by Nori and Seitzman in the case of methane-air flames [43]. This aspect is beyond the scope of the present study and requires an appropriate model to describe $\mathrm{CO}_{2}{ }^{*}$ chemiluminescence. The evolution of the $\mathrm{CH}^{*}$ emission peak height is well reproduced as illustrated in Figure 7.

\subsubsection{Analysis of the chemiluminescence intensity}

In hydrocarbon-based mixtures highly diluted with argon, the dynamics of excited $\mathrm{OH}$ radicals, $\mathrm{OH}^{*}$, can be approximated by the following reduced reaction scheme:

$$
\begin{gathered}
R_{1}^{\text {Chem }}: \mathrm{OH}^{*}=\mathrm{OH}+h \nu \\
R_{2}^{\text {Chem }}: \mathrm{OH}^{*}+\mathrm{M}=\mathrm{OH}+\mathrm{M} \\
R_{3}^{\text {Chem }}: \mathrm{CH}+\mathrm{O}_{2}=\mathrm{CO}+\mathrm{OH}^{*}
\end{gathered}
$$


Applying a quasi-steady-state analysis to $\mathrm{OH}^{*}$ leads to:

$$
\left[\mathrm{OH}^{*}\right]=\frac{[\mathrm{CH}]\left[\mathrm{O}_{2}\right] k_{3}}{1+\frac{k_{2}}{k_{1}}[\mathrm{M}]} .
$$

The chemiluminescence intensity is directly proportional to the concentration of $\mathrm{OH}^{*}$ so that:

$$
I_{\text {chem }}\left(\mathrm{OH}^{*}\right) \propto A \frac{[\mathrm{CH}]\left[\mathrm{O}_{2}\right] k_{3}}{1+\frac{k_{2}}{k_{1}}[\mathrm{M}]},
$$

where $A$ is a constant which accounts for the volume probed, the light collection solid angle and the efficiency of the detection system.

Considering that $\left[\mathrm{O}_{2}\right]$ is essentially constant, equation 9 can be re-written as:

$$
I_{\text {chem }}\left(\mathrm{OH}^{*}\right) \propto B F_{k}\left(\mathrm{OH}^{*}\right)[\mathrm{CH}]
$$

where

$$
B=A\left[\mathrm{O}_{2}\right]
$$

and

$$
F_{k}\left(\mathrm{OH}^{*}\right)=\frac{k_{3}}{1+\frac{k_{2}}{k_{1}}[\mathrm{M}]} .
$$

The magnitudes of the normalized values for $F_{k}\left(\mathrm{OH}^{*}\right),[\mathrm{CH}]_{\max }$, the experimental $\mathrm{OH}^{*}$ emission, and calculated $\mathrm{OH}^{*}$ (obtained with the detailed model) are compared in Figure 9. It is seen that the ratio $F_{k}\left(\mathrm{OH}^{*}\right)$ demonstrates a linear temperaturedependence whereas $[\mathrm{CH}]_{\max }$ exhibits an exponential dependence with temperature. The dominant parameter for the evolution of $\mathrm{OH}^{*}$ chemiluminescence is the concentration of its transient precursor: $\mathrm{CH}$ radicals.

In the case of $\mathrm{CH}^{*}$, the following reduced reaction scheme is used:

$$
\begin{gathered}
R_{4}^{\text {Chem }}: \mathrm{CH}^{*}=\mathrm{CH}+h \nu \\
R_{5}^{\text {Chem }}: \mathrm{CH}^{*}+\mathrm{M}=\mathrm{CH}+\mathrm{M} \\
R_{6}^{\text {Chem }}: \mathrm{C}_{2} \mathrm{H}+\mathrm{O}=\mathrm{CO}+\mathrm{CH}^{*}
\end{gathered}
$$

A similar quasi-steady-state analysis for $\mathrm{CH}^{*}$ leads to:

$$
I_{\text {chem }}\left(\mathrm{CH}^{*}\right) \propto A^{\prime} F_{k}(C H *)\left[\mathrm{C}_{2} \mathrm{H}\right][\mathrm{O}]
$$


where $A^{\prime}$ is a constant accounting for the optical system efficiency, and

$$
F_{k}\left(\mathrm{CH}^{*}\right)=\frac{k_{6}}{1+\frac{k_{5}}{k_{4}}[\mathrm{M}]} .
$$

Figure 10 displays the magnitudes of the normalized values for $F_{k}\left(\mathrm{CH}^{*}\right),\left(\left[\mathrm{C}_{2} \mathrm{H}\right] \times[\mathrm{O}]\right)_{\max }$, the experimental $\mathrm{CH}^{*}$ emission, and calculated $\mathrm{CH}^{*}$. Similar to $\mathrm{OH}^{*}$, the ratio $F_{k}\left(\mathrm{CH}^{*}\right)$ demonstrates a linear temperature-dependence whereas $\left(\left[\mathrm{C}_{2} \mathrm{H}\right] \times[\mathrm{O}]\right)_{\max }$ exhibits an exponential dependence with temperature. This indicates that the leading order parameter for the evolution of $\mathrm{CH}^{*}$ chemiluminescence with temperature is the concentration of its transient precursors: $\mathrm{C}_{2} \mathrm{H}$ and $\mathrm{O}$.

In the case of $\mathrm{CO}_{2}{ }^{*}$, the correlation from Slack and Grillo [38] demonstrates the dominant role of $[\mathrm{CO}]$ and $[\mathrm{O}]$ but predicts an exponential dependence with temperature of $F_{k}\left(\mathrm{CO}_{2}^{*}\right)=6.8 .10^{5} \exp \left(\frac{-16295}{R T}\right) \mathrm{cm}^{3} / \mathrm{mol}$, rather than a linear one. A more consistent sub-model is required for $\mathrm{CO}_{2}$ * in order to draw definite conclusions about the temperature dependence of the chemiluminescence intensity.

These observations for $\mathrm{OH}^{*}, \mathrm{CH}^{*}$ and $\mathrm{CO}_{2}{ }^{*}$ indicate that the chemiluminescence processes are dominated by the dynamics of the ground-state chemical species. This is consistent with previous results $[15,42]$ obtained on chemiluminescence processes in shock-tube experiments. As previously mentioned, the experimental uncertainty is too large to discriminate between the delay-times obtained with the different chemiluminescence signals. The ground-state dynamics controls the formation of the excited species and the formation time-scale of the three excited species are predicted by the model to be different. Figure 11 shows an example of calculated normalized profiles for the excited species and their precursors. Both $\mathrm{OH}^{*}$ and $\mathrm{CH}^{*}$ peak at very similar times and correlate well with the peak of the energy release rate, i.e. the temperature derivative. On the contrary, $\mathrm{CO}_{2}{ }^{*}$ peaks about $40 \mu \mathrm{s}$ after the temperature derivative peak located at about $190 \mu \mathrm{s}$. This is due to the broad profile of $\mathrm{CO}$ as well as the delayed formation of $\mathrm{O}$ atoms. This indicates that $\mathrm{OH}^{*}$ and $\mathrm{CH}^{*}$ can be considered as reliable ignition markers whereas $\mathrm{CO}_{2}{ }^{*}$, if measured alone, could lead to overestimated ignition delay-time. This conclusions 
is likely mixture specific and will need to be investigated in other chemical systems.

\subsubsection{Sensitivity and chemical pathway analyses}

In order to determine the important chemical reactions for the oxidation of acrolein, sensitivity and reaction pathway analyses have been performed. Figure 12 shows the most sensitive reactions with respect to temperature. Calculations were performed for $\Phi=0.5,1$ and 2 , at $\mathrm{T}=1400 \mathrm{~K}$ and $\mathrm{P}=350 \mathrm{kPa}$. These sensitivity analyses demonstrate the importance of (i) the reactions between acrolein and oxygen atoms: $\mathrm{C}_{2} \mathrm{H}_{3} \mathrm{CHO}+\mathrm{O}=\mathrm{CH}_{2} \mathrm{O}+\mathrm{CH}_{2} \mathrm{CO} ; \mathrm{C}_{2} \mathrm{H}_{3} \mathrm{CHO}+\mathrm{O}=\mathrm{C}_{2} \mathrm{H}_{3}+\mathrm{OH}+\mathrm{CO}$; and $\mathrm{C}_{2} \mathrm{H}_{3} \mathrm{CHO}+\mathrm{O}=\mathrm{C}_{2} \mathrm{H}_{3} \mathrm{CO}+\mathrm{OH}$; (ii) the branching reaction $\mathrm{H}+\mathrm{O}_{2}=\mathrm{O}+\mathrm{OH}$; (iii) $\mathrm{HCO}$ chemistry: $\mathrm{HCO}+\mathrm{M}=\mathrm{CO}+\mathrm{H}+\mathrm{M}$ and $\mathrm{HCO}+\mathrm{O}_{2}=\mathrm{CO}+\mathrm{HO}_{2}$; and (iv) vinyl radical chemistry: $\mathrm{C}_{2} \mathrm{H}_{3}+\mathrm{OH}=\mathrm{CH}_{2} \mathrm{CHO}+\mathrm{O}$. These results are further emphasized in Figure 13 which summarizes the main reaction pathways during the oxidation of a stoichiometric acrolein-oxygen-argon mixture at $\mathrm{T}=1400 \mathrm{~K}$ and $\mathrm{P}=350 \mathrm{kPa}$. In the present model, acrolein consumption is balanced between hydrogen-abstraction reactions, 57\%, and dissociative reactions with $\mathrm{O}$ and $\mathrm{OH}, 40 \%$. The abstraction reactions products undergo $\mathrm{C}-\mathrm{C}$ bond rupture and lead to the formation of $\mathrm{CO}$ : $\mathrm{C}_{2} \mathrm{H}_{3} \mathrm{CO}=\mathrm{C}_{2} \mathrm{H}_{3}+\mathrm{CO}$; and $\mathrm{HCO}: \mathrm{CHCHCHO}=\mathrm{C}_{2} \mathrm{H}_{2}+\mathrm{HCO}$ and $\mathrm{CH}_{2} \mathrm{CCHO}=\mathrm{H}_{2} \mathrm{C}_{2}+\mathrm{HCO}$.

Vinyl radicals are formed via $\mathrm{C}_{2} \mathrm{H}_{3} \mathrm{CO}=\mathrm{C}_{2} \mathrm{H}_{3}+\mathrm{CO}$ and $\mathrm{C}_{2} \mathrm{H}_{3} \mathrm{CHO}+\mathrm{O}=\mathrm{C}_{2} \mathrm{H}_{3}+\mathrm{OH}+\mathrm{CO}$. Their consumption results in the formation of $\mathrm{C}_{2} \mathrm{H}_{2}: \mathrm{C}_{2} \mathrm{H}_{3}(+\mathrm{M})=\mathrm{C}_{2} \mathrm{H}_{2}+\mathrm{H}(+\mathrm{M})$; and $\mathrm{CH}_{2} \mathrm{O}: \mathrm{C}_{2} \mathrm{H}_{3}+\mathrm{O}_{2}=\mathrm{HCO}+\mathrm{CH}_{2} \mathrm{O}$. The formation of formaldehyde is also due to $\mathrm{C}_{2} \mathrm{H}_{3} \mathrm{CHO}+\mathrm{O}=\mathrm{CH}_{2} \mathrm{O}+\mathrm{CH}_{2} \mathrm{CO}$. Formaldehyde reacts mainly with $\mathrm{O}$ and $\mathrm{OH}$ to form $\mathrm{HCO}$ through $\mathrm{H}$-abstraction reactions. Acetylene is mainly formed from vinyl and acrolein radicals dissociation and consumed by reaction with $\mathrm{O}$ atom, which contributes to $14 \%$ of the CO production. Carbon monoxide production is dominated by reactions which involves $\mathrm{HCO}: \mathrm{HCO}+\mathrm{M}=\mathrm{CO}+\mathrm{H}+\mathrm{M}$ and $\mathrm{HCO}+\mathrm{O}_{2}=\mathrm{CO}+\mathrm{HO}_{2}$. Finally, $\mathrm{CO}_{2}$ is formed by: $\mathrm{CO}+\mathrm{OH}=\mathrm{CO}_{2}+\mathrm{H}$; which allows for the production of $\mathrm{H}$-atom and enhances the branching process.

To develop the present acrolein reaction model, we adopted the following procedure: 1) we replaced our acrolein reaction model, from [19], by that of JetSurf 
[21]; 2) we added a number of reactions based on an analogy with 1,3 butadiene; 3) we adjusted the 4 rate constants mentioned previously. The unimolecular reactions considered in JetSurf were $\mathrm{C}_{2} \mathrm{H}_{3} \mathrm{CHO}=\mathrm{C}_{2} \mathrm{H}_{3}+\mathrm{CHO}$ and $\mathrm{C}_{2} \mathrm{H}_{3} \mathrm{CHO}=\mathrm{CH}_{2} \mathrm{CHCO}+\mathrm{H}$. Moreover, $\mathrm{H}$-abstraction reactions in JeSurf were only included for the $\mathrm{H}$ atom of the aldehyde function. Because unimolecular and $\mathrm{H}$-abstraction reactions on the vinyl group were neglected, only one radical of acrolein was taken into account: $\mathrm{CH}_{2} \mathrm{CHCO}$. We added two unimolecular reactions: $\mathrm{C}_{2} \mathrm{H}_{3} \mathrm{CHO}=\mathrm{CH}_{2} \mathrm{CCHO}+\mathrm{H}$ and $\mathrm{C}_{2} \mathrm{H}_{3} \mathrm{CHO}=\mathrm{CHCHCHO}+\mathrm{H}$ along with $\mathrm{H}$-abstraction reactions for the vinylic $\mathrm{H}$ atoms. The reactions rate for these reactions were taken equal to those for $1,3 \mathrm{bu}-$ tadiene. This approach was motivated by the measured activation energies from the present and previous experimental results for various alkane-, alkene- and aldehydebased mixtures.

The dominant initiation reactions for the oxidation of acrolein are $\mathrm{C}_{2} \mathrm{H}_{3} \mathrm{CHO}=\mathrm{C}_{2} \mathrm{H}_{3}+\mathrm{CHO}$ and $\mathrm{C}_{2} \mathrm{H}_{3} \mathrm{CHO}=\mathrm{CH}_{2} \mathrm{CHCO}+\mathrm{H}$. Based on the $\mathrm{CO}_{2}{ }^{*}$ emission profiles, we slightly decreased the rate constant of the first reaction. With the original rate constant, double-peak $\mathrm{CO}_{2}{ }^{*}$ profiles were predicted by the model due to the too rapid formation of $\mathrm{HCO}$ which leads to $\mathrm{CO}$ and ultimately to $\mathrm{CO}_{2}{ }^{*}$. The contribution of $\mathrm{C}_{2} \mathrm{H}_{3} \mathrm{CHO}=\mathrm{C}_{2} \mathrm{H}_{3}+\mathrm{CHO}$ to acrolein consumption is about $20 \%$ higher than that of $\mathrm{C}_{2} \mathrm{H}_{3} \mathrm{CHO}=\mathrm{CH}_{2} \mathrm{CHCO}+\mathrm{H}$. This seems consistent with the relatively small difference of energy between the $\mathrm{C}-\mathrm{CHO}$ and the $\mathrm{H}-\mathrm{CO}$ bonds reported for aldehydes $[44]$.

The additions of these reactions along with a few rate constant modifications appears to be sufficient in reproducing the experimental activation energy and delaying the formation of $\mathrm{HCO}$ and $\mathrm{CO}$ via hydrogen-abstraction pathways. Nevertheless, it should be recognized that the present reaction model is tentative and can be substantially improved. We have made admittedly crude estimates of the reaction coefficients for reactions $R_{1}$ to $R_{4}$ which reproduced the experimental results. To our knowledge, there are no experimental determination nor reliable calculations available for these reaction rates. The reaction rate recommended by Tsang and Hampson [40] for the inverse of $\mathrm{R}_{1}: \mathrm{C}_{2} \mathrm{H}_{3}+\mathrm{HCO}=\mathrm{C}_{2} \mathrm{H}_{3} \mathrm{CHO}$ comes from an analogy with $\mathrm{CH}_{3}+\mathrm{HCO}=\mathrm{CH}_{3} \mathrm{CHO}$ and is given with an uncertainty factor of 3. Similar 
uncertainty can probably be considered for the other reaction rates we modified since they were already estimated in JetSurf. Additional experimental data are required to properly quantify the branching ratios of the initiation step during the auto-ignition of acrolein-oxygen mixtures. In particular, $\mathrm{C}_{2} \mathrm{H}_{2}, \mathrm{CH}_{2} \mathrm{O}$ and $\mathrm{CO}$ appear as important intermediates. Their accurate measurement, along with that of the $\mathrm{OH}$ radical, would help better characterize the reaction mechanism of acrolein oxidation.

\section{Conclusion}

In the present study, the ignition of acrolein-oxygen-argon mixtures has been investigated over the following ranges: $\Phi=0.5-2 ; \mathrm{T}_{5}=1178-1602 \mathrm{~K}$; and $\mathrm{P}_{5}=173-416$ $\mathrm{kPa}$. These data constitute, to our knowledge, the first available experimental measurements for this extremely toxic pollutant. It is shown that the activation energy of the ignition process seems to be mainly controlled by the unsaturated nature of the linear hydrocarbon chain and is not influenced by the aldehyde function. A tentative detailed reaction model was proposed based on existing kinetic data and an analogy with 1,3-butadiene to describe the high-temperature chemical kinetics of acrolein oxidation. Reasonable agreement with the experimental data was demonstrated. Sensitivity and reaction pathway analyses demonstrated the importance of reactions of acrolein with oxygen atom and of formaldehyde, vinyl radical and acetylene chemistry. The experimental data and the preliminary acrolein kinetic model developed in this work can be used to improve the understanding of the formation of toxic substances by biofuel combustion and mitigate their negative environmental footprint.

\section{Acknowledgements}

The present work was carried out in the Explosion Dynamics Laboratory and the Turbulent Flow Oriented Research in Combustion and Energy groups of the California Institute of Technology. Karl Chatelain is grateful to the "Conseil Régional du Centre" for sponsoring a student fellowship during his stay at Caltech. 


\section{References}

[1] Akih-Kumgeh B, Bergthorson JM. Ignition of C3 oxygenated hydrocarbons and chemical kinetic modeling of propanal oxidation. Combust Flame 2011;158:1877-1889.

[2] Zhang J, Pan L, Mo J, Gong J, Huang Z, Law CK. A shock tube and kinetic modeling study of n-butanal oxidation. Combust Flame 2013;160:1541-1549.

[3] Posada F., Malins C., Baral A. Biodiesel carbon intensity, sustainability and effects on vehicles and emissions. Technical report, The International Council on Clean Transportation, 2012.

[4] van Renssen S. A biofuel conundrum. Nature Clim. Change 2011;1:389-390.

[5] He C, Ge Y, Tan J, You K, Han X, Wang J, You Q, Shah AN. Comparison of carbonyl compounds emissions from diesel engine fueled with biodiesel and diesel. Atmos Environ 2009;43:3657-3661.

[6] Guarieiro LLN, de Souza AF, Torres EA, de Andrade JB. Emission profile of 18 carbonyl compounds, $\mathrm{CO}, \mathrm{CO}_{2}$, and nox emitted by a diesel engine fuelled with diesel and ternary blends containing diesel, ethanol and biodiesel or vegetable oils. Atmos Environ 2009;43:2754-2761.

[7] Davidson D, Ranganath S, Lam KY, Liaw M, Hong Z, Hanson R. Ignition delay time measurements of normal alkanes and simple oxygenates. J Propul Power 2010;26:280-287.

[8] Veloo PS, Dagaut P, Togbé C, Dayma G, Sarathy SM, Westbrook CK, Egolfopoulos FN. Experimental and modeling study of the oxidation of n- and isobutanal. Combust Flame 2013;160:1609-1626.

[9] Black G, Curran H, Pichon S, Simmie J, Zhukov V. Bio-butanol: Combustion properties and detailed chemical kinetic model. Combust Flame 2010;157:363373. 
[10] Fontaras G, Karavalakis G, Kousoulidou M, Ntziachristos L, Bakeas E, Stournas S, Samaras Z. Effects of low concentration biodiesel blends application on modern passenger cars. part 2: Impact on carbonyl compound emissions. Environ Pollut 2010;158:2496-2503.

[11] Asatryan R, da Silva G, Bozzelli J. Quantum chemical study of the acrolein $\left(\mathrm{CH}_{2} \mathrm{CHCHO}\right)+\mathrm{OH}+\mathrm{O}_{2}$ reactions. J Phys Chem A 2010;114:8302-8311.

[12] Faroon O, Roney N, Taylor J, Ashizawa A, Lumpkin M, Plewak D. Acrolein health effects. Toxicol Ind Health 2008;24:447-490.

[13] Dagaut P, El Bakali A, Ristori A. The combustion of kerosene: experimental results and kinetic modelling using 1- to 3-component surrogate model fuels. Fuel 2006;85:944-956.

[14] Orlando J, Tyndall G. Mechanisms for the reactions of oh with two unsaturated aldehydes: Crotonaldehyde and acrolein. J Phys Chem A 2002;106:12252-12259.

[15] Mével R, Pichon S, Catoire L, Chaumeix N, Paillard CE, Shepherd JE. Dynamics of excited hydroxyl radicals in hydrogen-based mixtures behind reflected shock waves. Proc Combust Inst 2013;34:677-684.

[16] Mével R, Shepherd JE. Ignition delay-time behind reflected shock waves of small hydrocarbons-nitrous oxide(-oxygen) mixtures. Shock Waves in press.

[17] Mével R, Javoy S, Lafosse F, Chaumeix N, Dupré G, Paillard CE.. Hydrogennitrous oxide delay time: shock tube experimental study and kinetic modelling. Proc Combust Inst 2009;32:359-366.

[18] Mével R, Javoy S, Dupré G. A chemical kinetic study of the oxidation of silane by nitrous oxide, nitric oxide and oxygen. Proc Combust Inst 2001;33:485-492.

[19] Blanquart G, Pepiot-Desjardins P, Pitsch H. Chemical mechanism for high temperature combustion of engine relevant fuels with emphasis on soot precursors, Combust Flame 2009;156:588-607. 
[20] Le Cong T. Etude expérimentale et modélisation de la cinétique de combustion de combustibles gazeux : Méthane, gaz naturel et mélanges contenant de l'hydrogène, du monoxyde de carbone, du dioxyde de carbone et de l'eau, Ph.D. thesis, Université d'Orléans; 2007.

[21] Sirjean B, Dames E, Sheen DA, You XQ, Sung C, Holley AT, Egolfopoulos FN, Wang H, Vasu SS, Davidson DF, Hanson RK, Pitsch H, Bowman CT, Kelley A, Law CK, Tsang W, Cernansky NP, Miller DL, Violi A, Lindstedt RP. A high-temperature chemical kinetic model of n-alkane oxidation, jetsurf version 0.2. Available at: http://melchior.usc.edu/JetSurF/Version $0_{2} /$ Index.html; 2008 .

[22] Hall J, Rickard M, Petersen E. Comparison of characteristic time diagnostics for ignition and oxidation of fuel/oxidizer mixtures behind reflected shock waves. Combust Sci Technol 2005;177:455-483.

[23] Hall J, Petersen E. An optimized kinetics model for OH chemiluminescence at high temperature and atmospheric pressures. Int J Chem Kinet 2006;38:714724 .

[24] Hidaka Y, Takuma H, Suga M. Shock-tube study of the rate constant for excited $\mathrm{OH}^{*}\left(A^{2} \Sigma^{+}\right)$formation in the $\mathrm{N}_{2} \mathrm{O}-\mathrm{H}_{2}$ reaction. J Phys Chem 1985;89:49034905.

[25] Hidaka Y, Takahashi S, Kawano H, Suga M. Shock-tube measurement of the rate constant for excited $\mathrm{OH}\left(A^{2} \Sigma^{+}\right)$formation in the hydrogen-oxygen reaction. J Phys Chem 1982;86:1429-1433.

[26] Devriendt K, Van Look H, Ceursters B, Peeters J. Kinetics of formation of chemiluminescent $\mathrm{CH}\left(\mathrm{A}^{2} \Delta\right)$ by the elementary reactions of $\mathrm{C}_{2} \mathrm{H}\left(\mathrm{X}^{2} \Sigma^{+}\right)$ with $\mathrm{O}\left({ }^{3} \mathrm{p}\right)$ and $\mathrm{O}_{2}\left(\mathrm{X}^{2} \Sigma_{g}^{-}\right)$: a pulse laser photolysis study. Chem Phys Lett 1996;261:450-456.

[27] Smith G, Luque J, Park C, Jeffries J, Crosley D. Low pressure flame determi- 
nation of rate constants for $\mathrm{OH}(\mathrm{A})$ and $\mathrm{CH}(\mathrm{A})$ chemiluminescence. Combust Flame 2002;131:59-69.

[28] Kopp M, Brower M, Mathieu O, Petersen E, Guthe F. CO $\mathrm{O}_{2}^{*}$ chemiluminescence study at low and elevated pressures. Appl Phys B 2012;107:529-538.

[29] Sulzmann K, Myers B, Bartle E. CO oxidation. I. Induction period preceding $\mathrm{CO}_{2}$ formation in shock-heated CO-O 2 -Ar mixtures, J Chem Phys 1965;42:39693979.

[30] Blanquart G, Pitsch H. Thermochemical properties of polycyclic aromatic hydrocarbons (PAH) from G3MP2B3 calculations. J Phys Chem A 2007;111:65106520 .

[31] Lutz A, Kee R, Miller A. Senkin: a fortran program for predicting homogeneous gas phase chemical kinetics with sensitivity analysis. Tech. Rep. Sand87-8248, Sandia International Laboratories; 1992.

[32] Lamoureux N, Paillard CE, Vaslier V. Low hydrocarbon mixtures ignition delay times investigation behind reflected shock waves. Shock Waves 2002;11:309-322.

[33] Horning D, Davidson D, Hanson R. Study of the high-temperature autoignition of n-alkane/O $\mathrm{O}_{2} /$ Ar mixtures. J Propul Power 2002;18:363-371.

[34] Rotavera B, Dievart P, Togbe C, Dagaut P, Petersen E. Oxidation kinetics of n-nonane: Measurements and modeling of ignition delay times and product concentrations. Proc Combust Inst 2011;33:175-183.

[35] Kalitan D, Hall J, Petersen E. Ignition and oxidation of ethylene-oxygen-diluent mixtures with and without silane. J Propul Power 2005;21:1045-1056.

[36] Horning D. A study of the high-temperature autoignition and thermal decomposition of hydrocarbons, Ph.D. thesis, Stanford University; 2001.

[37] Libby C, Davidson DF, Hanson RK. A shock tube study of the oxidation of 1,3-butadiene. AIAA Paper 2004-1322. 
[38] Slack M, Grillo A. High temperature rate coefficient measurements of $\mathrm{CO}+\mathrm{O}$ chemiluminescence. Combust Flame 1985;59:189-196.

[39] You X, Wang H, Goos E, Sung CJ, Klippenstein SJ. Reaction kinetics of CO + $\mathrm{HO}_{2} \rightarrow$ products: Ab initio transition state theory study with master equation modeling. J Phys Chem A 2007;111:4031-4042.

[40] Tsang W, Hampson R. Chemical kinetic data base for combustion chemistry. Part I. Methane and related compounds. J Phys Chem Ref Data 1986;15:10871222 .

[41] Mével R, Lafosse F, Catoire L, Chaumeix N, Dupré G, Paillard CE. Induction delay times and detonation cell size prediction of hydrogen-nitrous oxide-argon mixtures, Combust Sci Technol 2009;180:1858-1875.

[42] Mével R, Javoy S, Coudoro K, Dupré G, Paillard CE. Assessment of $\mathrm{H}_{2}-\mathrm{CH}_{4}$-Air mixtures oxidation kinetic models used in combustion. Int J Hydrogen Energy 2012;37:698-714.

[43] Nori V, Seitzman J. Evaluation of chemiluminescence as a combustion diagnostic under varying operating conditions. AIAA Paper 2008-0953.

[44] da Silva G., Bozzelli J.W. Enthalpies of formation, bond dissociation energies, and molecular structures of the n-aldehydes (acetaldehyde, propanal, butanal, pentanal, hexanal, and heptanal) and their radicals. J Phys Chem A 2006;110:13058-13067. 


\begin{tabular}{ccccccc}
$\mathrm{N}$ & $\Phi$ & $\mathrm{X}_{A C R O}$ & $\mathrm{X}_{O 2}$ & $\mathrm{X}_{A r}$ & $\mathrm{~T}_{5}(\mathrm{~K})$ & $\mathrm{P}_{5}(\mathrm{kPa})$ \\
\hline 1 & 0.5 & 0.0038 & 0.0266 & 0.9696 & $1178-1458$ & $358-381$ \\
2 & 1 & 0.007 & 0.0245 & 0.9685 & $1168-1539$ & $173-416$ \\
3 & 2 & 0.011 & 0.019 & 0.9698 & $1179-1602$ & $305-386$
\end{tabular}

Table 1: Mixture compositions and experimental conditions examined in the present study. 


\begin{tabular}{|c|c|c|c|c|c|c|}
\hline $\mathrm{N}$ & $\Phi$ & $\mathrm{T}_{5}(\mathrm{~K})$ & $\mathrm{P}_{5}(\mathrm{kPa})$ & $\tau_{50 \%}\left(C O_{2} *\right)(\mu \mathrm{s})$ & $\tau_{100 \%}\left(C O_{2} *\right)(\mu \mathrm{s})$ & Peak height $\mathrm{CO}^{*}(-)$ \\
\hline 1 & 2.00 & 1179 & 386 & 692 & 763 & 0.18 \\
\hline 2 & 2.00 & 1225 & 347 & 429 & 504 & 0.22 \\
\hline 3 & 2.00 & 1225 & 374 & 481 & 550 & 0.21 \\
\hline 4 & 2.00 & 1288 & 349 & 306 & 353 & 0.30 \\
\hline 5 & 2.00 & 1365 & 345 & 158 & 184 & 0.43 \\
\hline 6 & 2.00 & 1435 & 336 & 108 & 133 & 0.56 \\
\hline 8 & 2.00 & 1602 & 305 & 51 & 65 & 1.00 \\
\hline 9 & 0.50 & 1178 & 370 & 523 & 615 & 0.37 \\
\hline 10 & 0.50 & 1220 & 363 & 411 & 460 & 0.38 \\
\hline 11 & 0.50 & 1316 & 359 & 135 & 175 & 0.57 \\
\hline 12 & 0.50 & 1316 & 381 & 117 & 128 & 0.63 \\
\hline 13 & 0.50 & 1365 & 358 & 85 & 99 & 0.70 \\
\hline 14 & 0.50 & 1458 & 360 & 44 & 62 & 1.00 \\
\hline 17 & 1.00 & 1242 & 415 & 280 & 311 & - \\
\hline 18 & 1.00 & 1252 & 373 & 286 & 330 & - \\
\hline 26 & 1.00 & 1337 & 371 & 162 & 193 & - \\
\hline 28 & 1.00 & 1360 & 352 & 116 & 135 & - \\
\hline 31 & 1.00 & 1367 & 323 & 103 & 117 & - \\
\hline 35 & 1.00 & 1539 & 314 & 33 & 45 & - \\
\hline
\end{tabular}

Table 2: Summary of the experimental results obtained from $\mathrm{CO}_{2}{ }^{*}$ emission for reflected shockheated $\mathrm{C}_{2} \mathrm{H}_{3} \mathrm{CHO}-\mathrm{O}_{2}$-Ar mixtures. 
Table 3: Summary of the experimental results obtained from $\mathrm{OH}^{*}$ emission for reflected shockheated $\mathrm{C}_{2} \mathrm{H}_{3} \mathrm{CHO}-\mathrm{O}_{2}$-Ar mixtures.

\begin{tabular}{|c|c|c|c|c|c|c|}
\hline $\mathrm{N}$ & $\Phi$ & $\mathrm{T}_{5}(\mathrm{~K})$ & $\mathrm{P}_{5}(\mathrm{kPa})$ & $\tau_{50 \%}(O H *)(\mu \mathrm{s})$ & $\tau_{100 \%}(O H *)(\mu \mathrm{s})$ & Peak height $\mathrm{OH}^{*}(-)$ \\
\hline 1 & 2.00 & 1179 & 386 & 652 & 728 & 0.20 \\
\hline 2 & 2.00 & 1225 & 347 & 425 & 476 & 0.24 \\
\hline 3 & 2.00 & 1225 & 374 & 474 & 515 & 0.26 \\
\hline 4 & 2.00 & 1288 & 349 & 311 & 346 & 0.36 \\
\hline 5 & 2.00 & 1365 & 345 & 150 & 182 & 0.62 \\
\hline 6 & 2.00 & 1435 & 336 & 113 & 136 & 0.73 \\
\hline 7 & 2.00 & 1522 & 329 & 66 & 120 & - \\
\hline 8 & 2.00 & 1602 & 305 & 51 & 66 & 1.00 \\
\hline 9 & 0.50 & 1178 & 370 & 490 & 554 & 0.09 \\
\hline 10 & 0.50 & 1220 & 363 & 407 & 440 & 0.22 \\
\hline 11 & 0.50 & 1316 & 359 & 143 & 165 & 0.44 \\
\hline 12 & 0.50 & 1316 & 381 & 117 & 139 & 0.52 \\
\hline 13 & 0.50 & 1365 & 358 & 84 & 108 & 0.58 \\
\hline 14 & 0.50 & 1458 & 360 & 47 & 63 & 1.00 \\
\hline 15 & 1.00 & 1168 & 241 & 1030 & 1066 & - \\
\hline 16 & 1.00 & 1169 & 173 & 1128 & 1194 & - \\
\hline 19 & 1.00 & 1252 & 248 & 403 & 426 & - \\
\hline 20 & 1.00 & 1258 & 416 & 450 & 471 & - \\
\hline 21 & 1.00 & 1285 & 231 & 278 & 304 & - \\
\hline 22 & 1.00 & 1300 & 240 & 237 & 256 & - \\
\hline 23 & 1.00 & 1307 & 244 & 231 & 253 & - \\
\hline 24 & 1.00 & 1323 & 245 & 210 & 229 & - \\
\hline 25 & 1.00 & 1329 & 251 & 142 & 158 & - \\
\hline 27 & 1.00 & 1360 & 257 & 158 & 175 & - \\
\hline 28 & 1.00 & 1360 & 352 & 119 & 135 & - \\
\hline
\end{tabular}




\begin{tabular}{|c|c|c|c|c|c|c|}
\hline $\mathrm{N}$ & $\Phi$ & $\mathrm{T}_{5}(\mathrm{~K})$ & $\mathrm{P}_{5}(\mathrm{kPa})$ & $\tau_{50 \%}(O H *)(\mu \mathrm{s})$ & $\tau_{100 \%}(O H *)(\mu \mathrm{s})$ & Peak height $\mathrm{OH}^{*}(-)$ \\
\hline 30 & 1.00 & 1366 & 382 & 121 & 135 & - \\
\hline 31 & 1.00 & 1367 & 323 & 101 & 117 & - \\
\hline 32 & 1.00 & 1376 & 262 & 128 & 144 & - \\
\hline 33 & 1.00 & 1440 & 236 & 70 & 86 & - \\
\hline 34 & 1.00 & 1450 & 343 & 49 & 61 & - \\
\hline 35 & 1.00 & 1539 & 314 & 34 & 48 & - \\
\hline
\end{tabular}




\begin{tabular}{|c|c|c|c|c|c|c|}
\hline $\mathrm{N}$ & $\Phi$ & $\mathrm{T}_{5}(\mathrm{~K})$ & $\mathrm{P}_{5}(\mathrm{kPa})$ & $\tau_{50 \%}(C H *)(\mu \mathrm{s})$ & $\tau_{100 \%}(C H *)(\mu \mathrm{s})$ & Peak height $\mathrm{CH}^{*}(-)$ \\
\hline 1 & 2.00 & 1179 & 386 & 701 & 745 & 0.07 \\
\hline 2 & 2.00 & 1225 & 347 & 448 & 484 & 0.14 \\
\hline 3 & 2.00 & 1225 & 374 & 498 & 535 & 0.13 \\
\hline 4 & 2.00 & 1288 & 349 & 325 & 348 & 0.28 \\
\hline 5 & 2.00 & 1365 & 345 & 170 & 187 & 0.61 \\
\hline 6 & 2.00 & 1435 & 336 & 115 & 135 & - \\
\hline 7 & 2.00 & 1522 & 329 & 97 & 136 & - \\
\hline 8 & 2.00 & 1602 & 305 & 52 & 70 & 1.00 \\
\hline 9 & 0.50 & 1178 & 370 & 508 & 599 & 0.07 \\
\hline 10 & 0.50 & 1220 & 363 & 407 & 443 & 0.11 \\
\hline 11 & 0.50 & 1316 & 359 & 140 & 165 & 0.27 \\
\hline 12 & 0.50 & 1316 & 381 & 115 & 133 & 0.37 \\
\hline 13 & 0.50 & 1365 & 358 & 86 & 103 & 0.43 \\
\hline 14 & 0.50 & 1458 & 360 & 45 & 62 & 1.00 \\
\hline 22 & 1.00 & 1300 & 240 & 226 & 251 & - \\
\hline 28 & 1.00 & 1360 & 352 & 114 & 131 & - \\
\hline 29 & 1.00 & 1364 & 367 & 117 & 128 & - \\
\hline 31 & 1.00 & 1367 & 323 & 98 & 112 & - \\
\hline 35 & 1.00 & 1539 & 314 & 31 & 43 & - \\
\hline
\end{tabular}

Table 4: Summary of the experimental results obtained from $\mathrm{CH}^{*}$ emission for reflected shockheated $\mathrm{C}_{2} \mathrm{H}_{3} \mathrm{CHO}-\mathrm{O}_{2}$-Ar mixtures. 


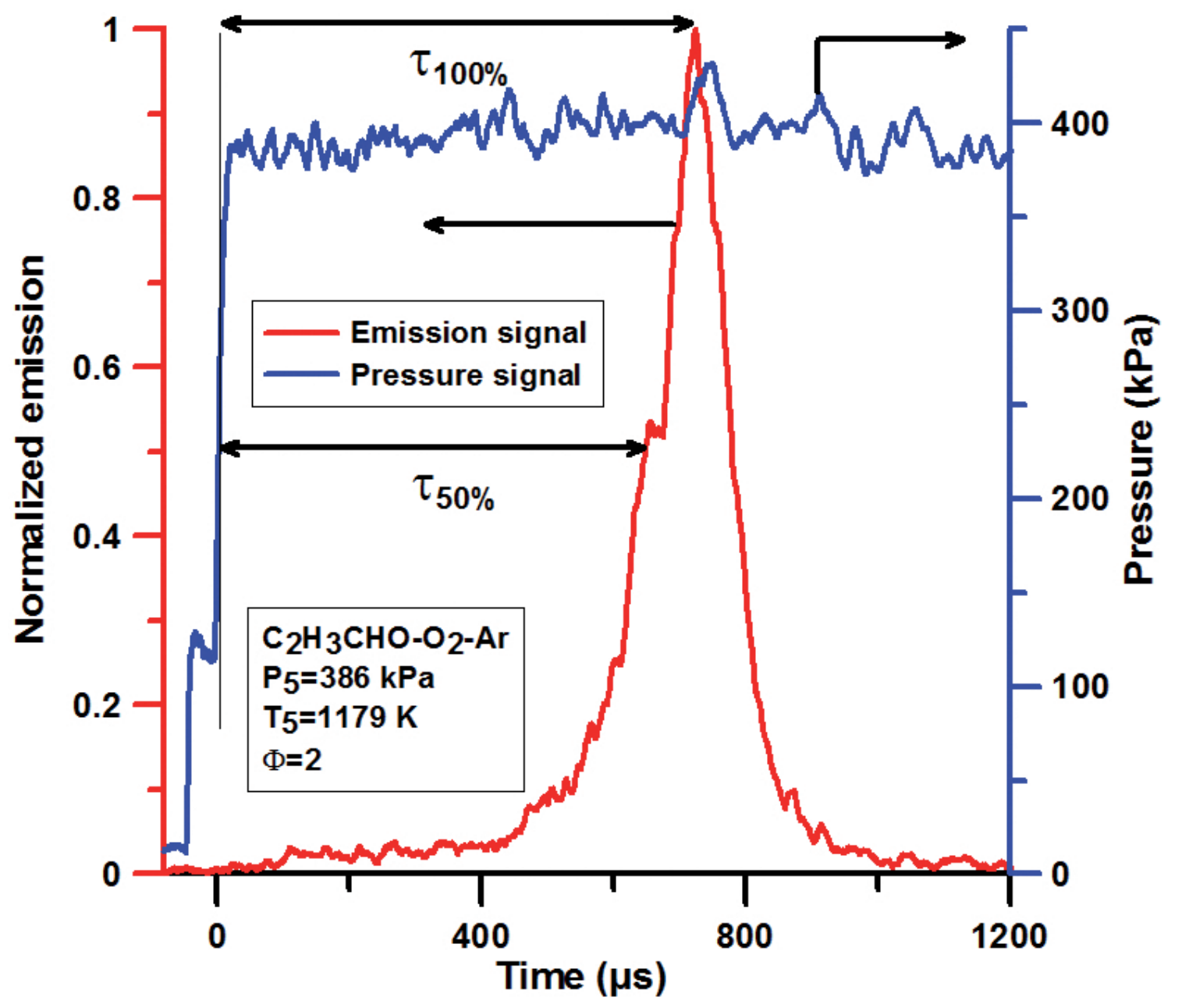

Figure 1: Typical experimental signals, pressure and $\mathrm{OH}^{*}$ emission, and definitions of the two characteristic times of reaction. 

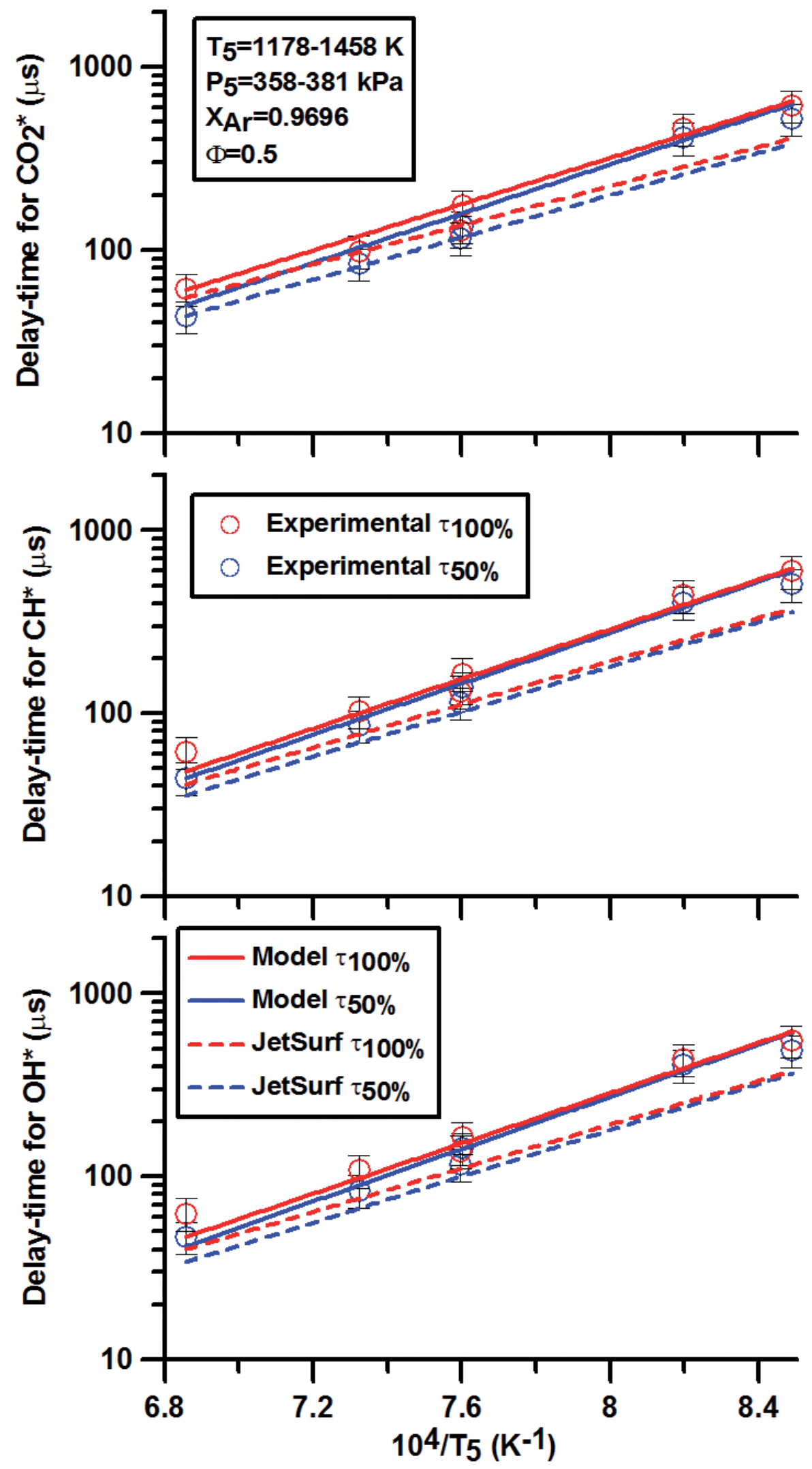

Figure 2: Experimental and calculated auto-ignition delay-times of a lean acrolein-oxygen-argon mixture. Solid lines: present model. Dashed lines: JetSurf. 

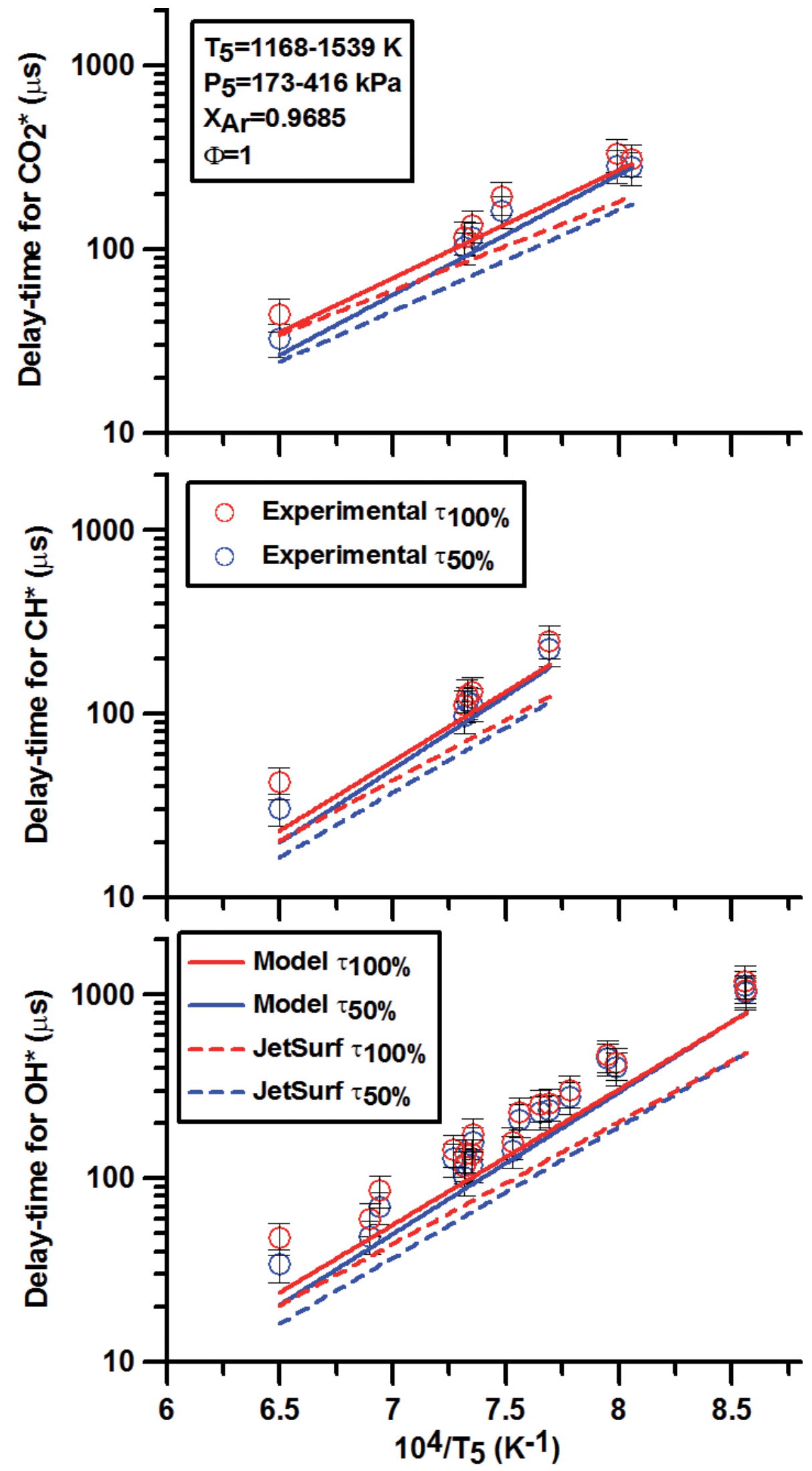

Figure 3: Experimental and calculated auto-ignition delay-times of a stoichiometric acroleinoxygen-argon mixture. Solid lines: present model. Dashed lines: JetSurf. 

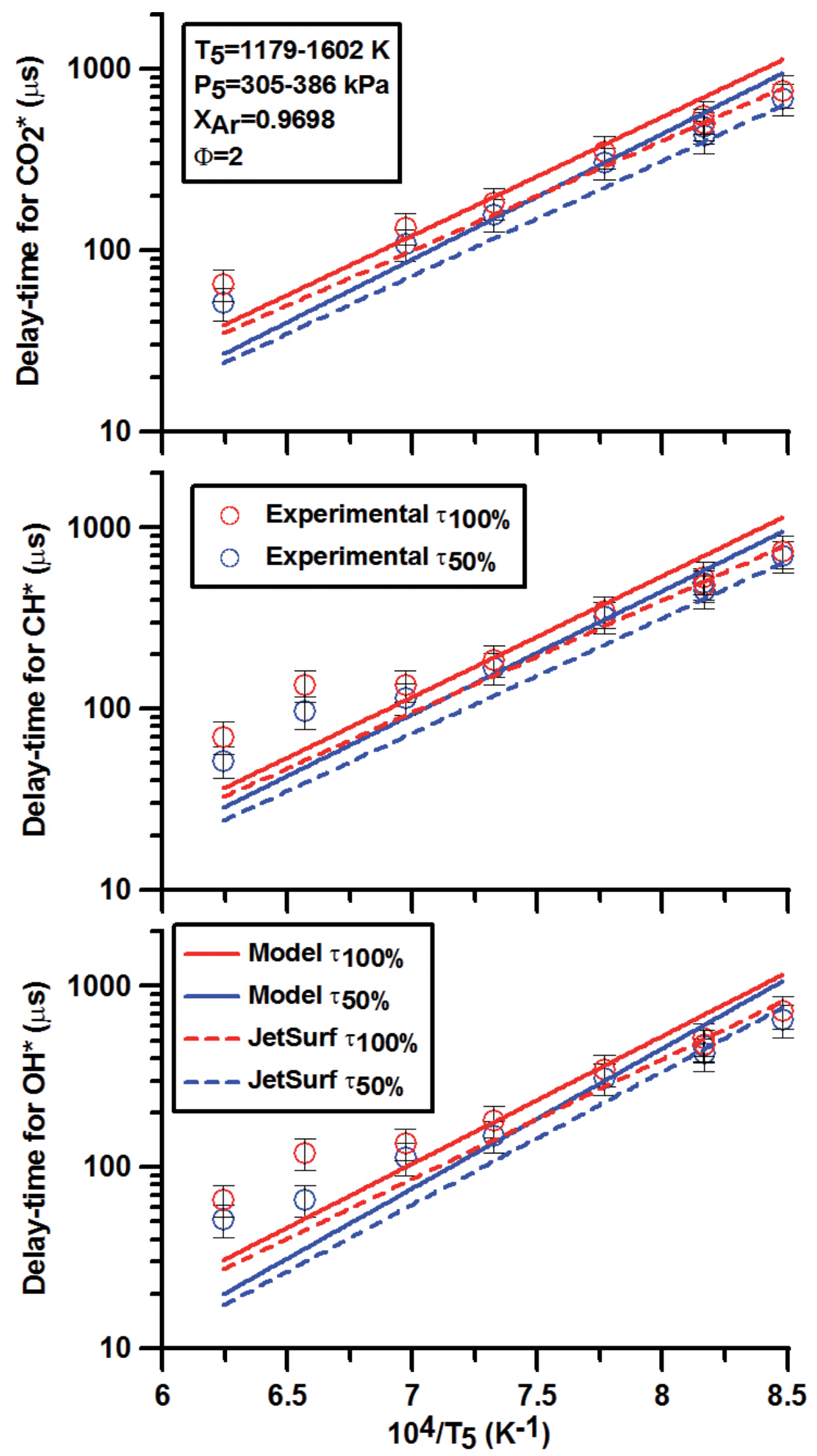

Figure 4: Experimental and calculated auto-ignition delay-times of a rich acrolein-oxygen-argon mixture. Solid lines: present model. Dashed lines: JetSurf. 


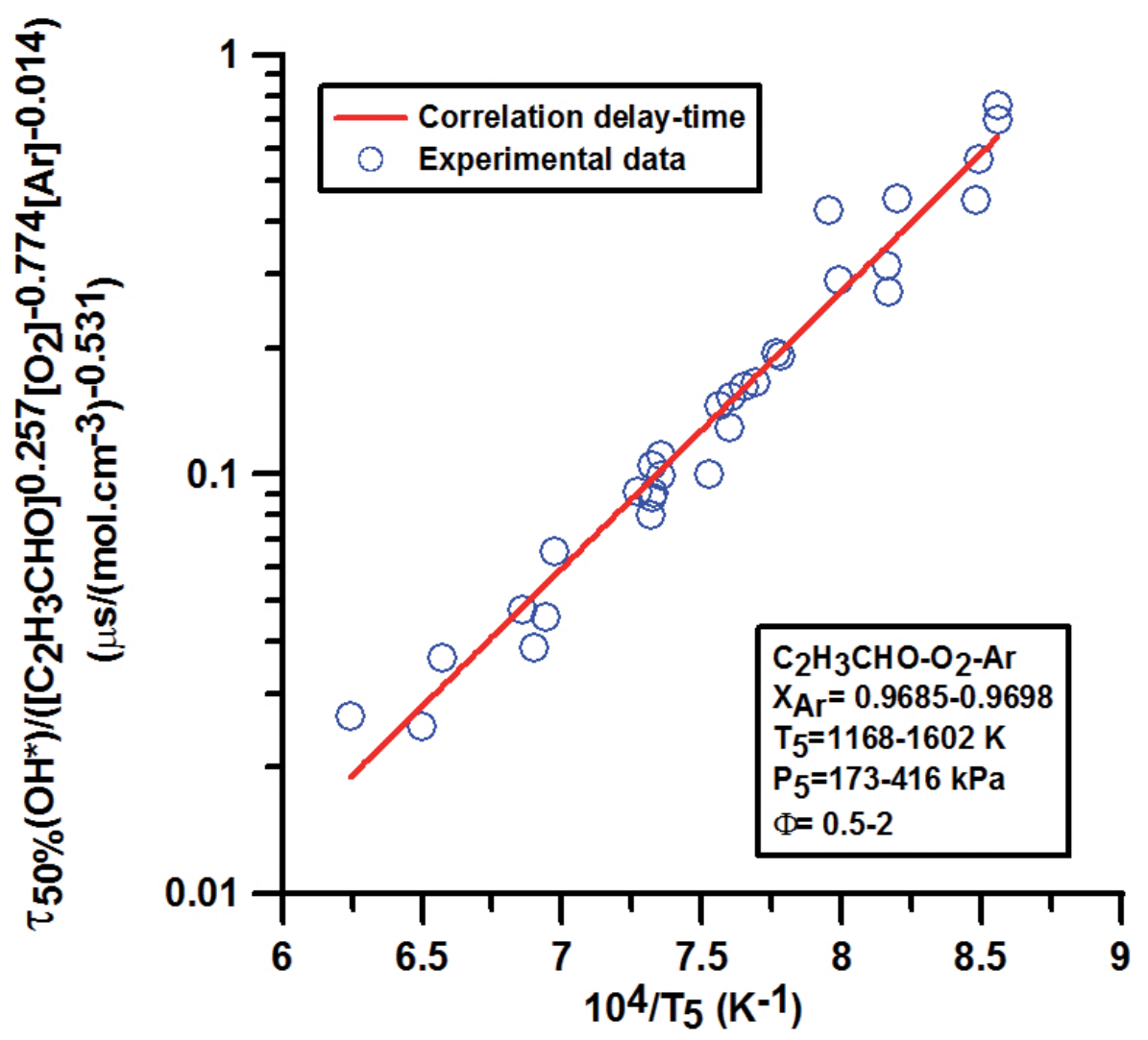

Figure 5: Comparison between normalized $\tau_{50 \%}\left(\mathrm{OH}^{*}\right)$ for acrolein-oxygen-argon mixtures obtained experimentally and predicted from the empirical correlation. 


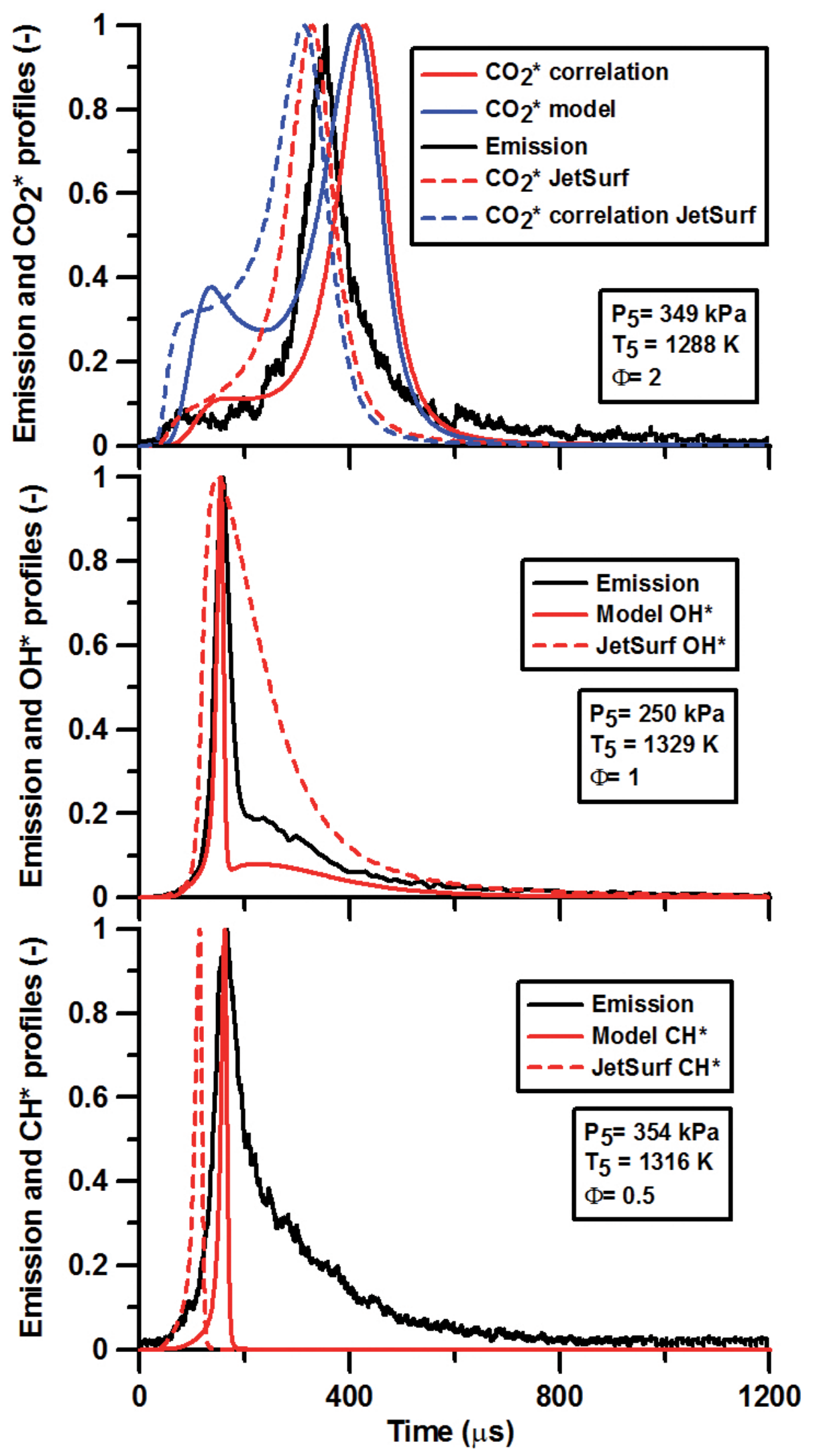

Figure 6: Experimental and predicted normalized $\mathrm{CO}_{2}{ }^{*}, \mathrm{OH}^{*}$ and $\mathrm{CH}^{*}$ profiles for acrolein-oxygenargon mixtures. Solid lines: present model. Dashed lines: JetSurf. 

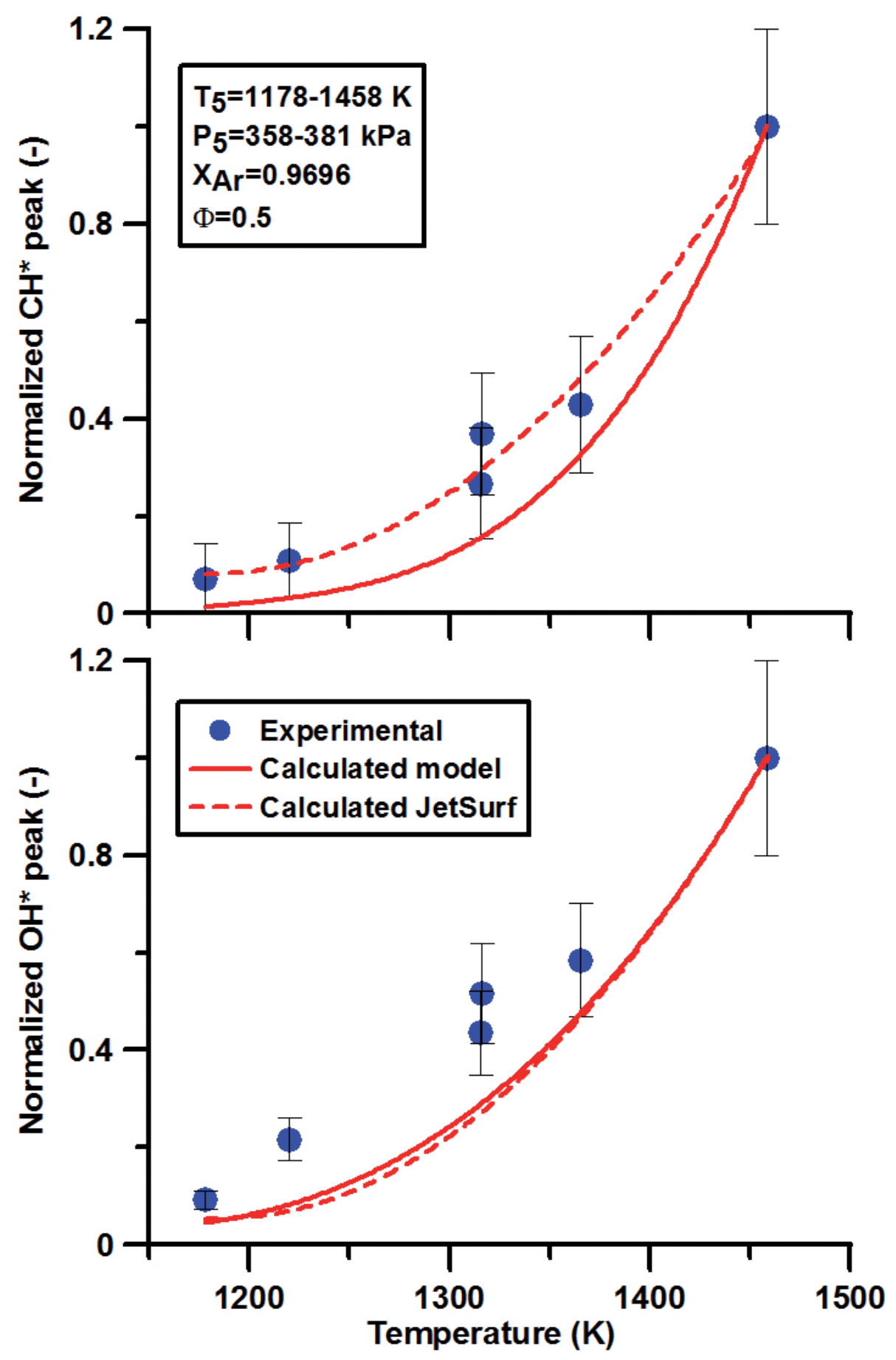

Figure 7: Experimental and calculated normalized peak height as a function of temperature for a lean acrolein-oxygen mixture. Solid lines: present model. Dashed lines: JetSurf. 

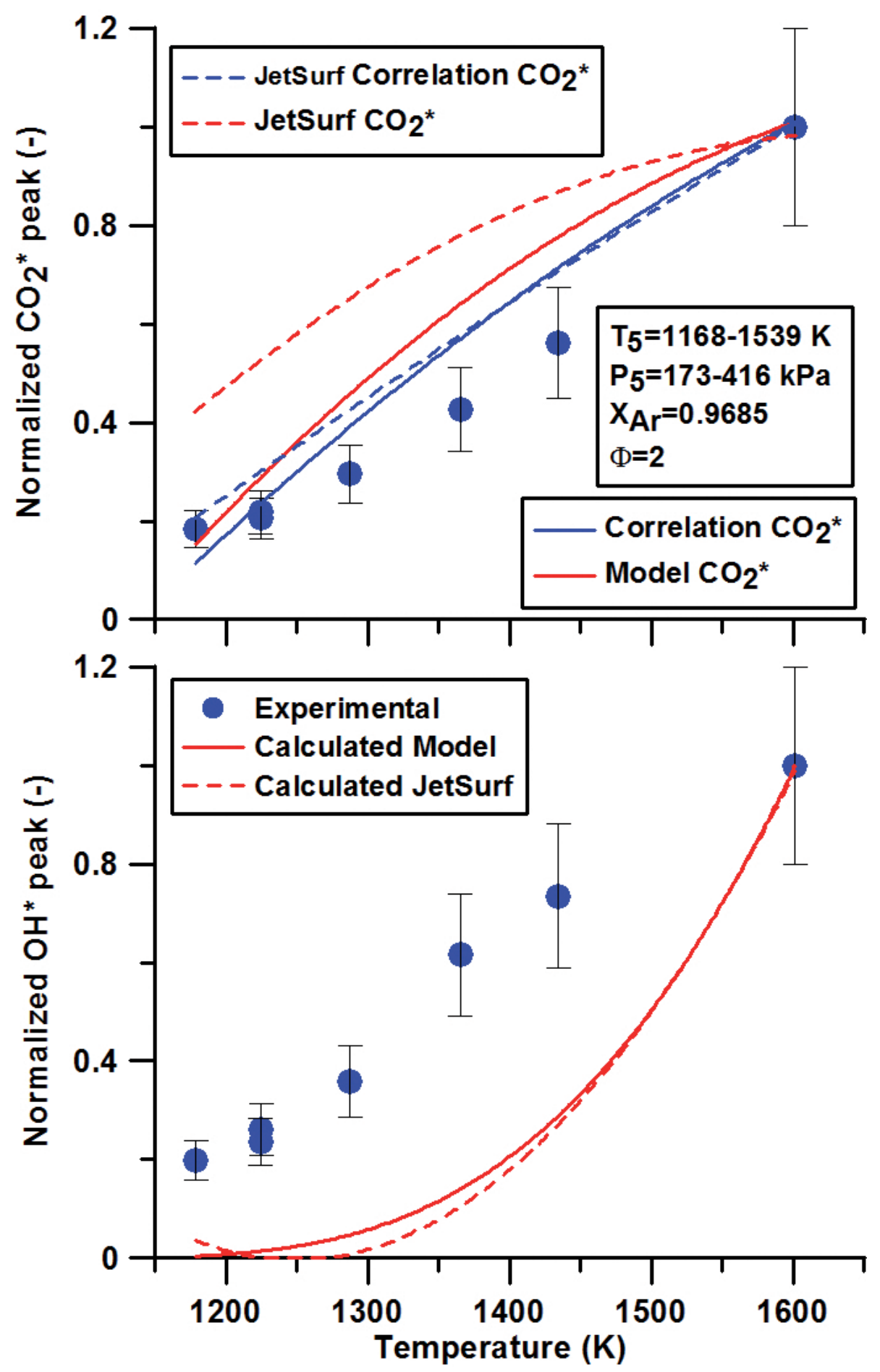

Figure 8: Experimental and calculated normalized peak height as a function of temperature for a rich acrolein-oxygen mixture. Solid lines: present model. Dashed lines: JetSurf. 


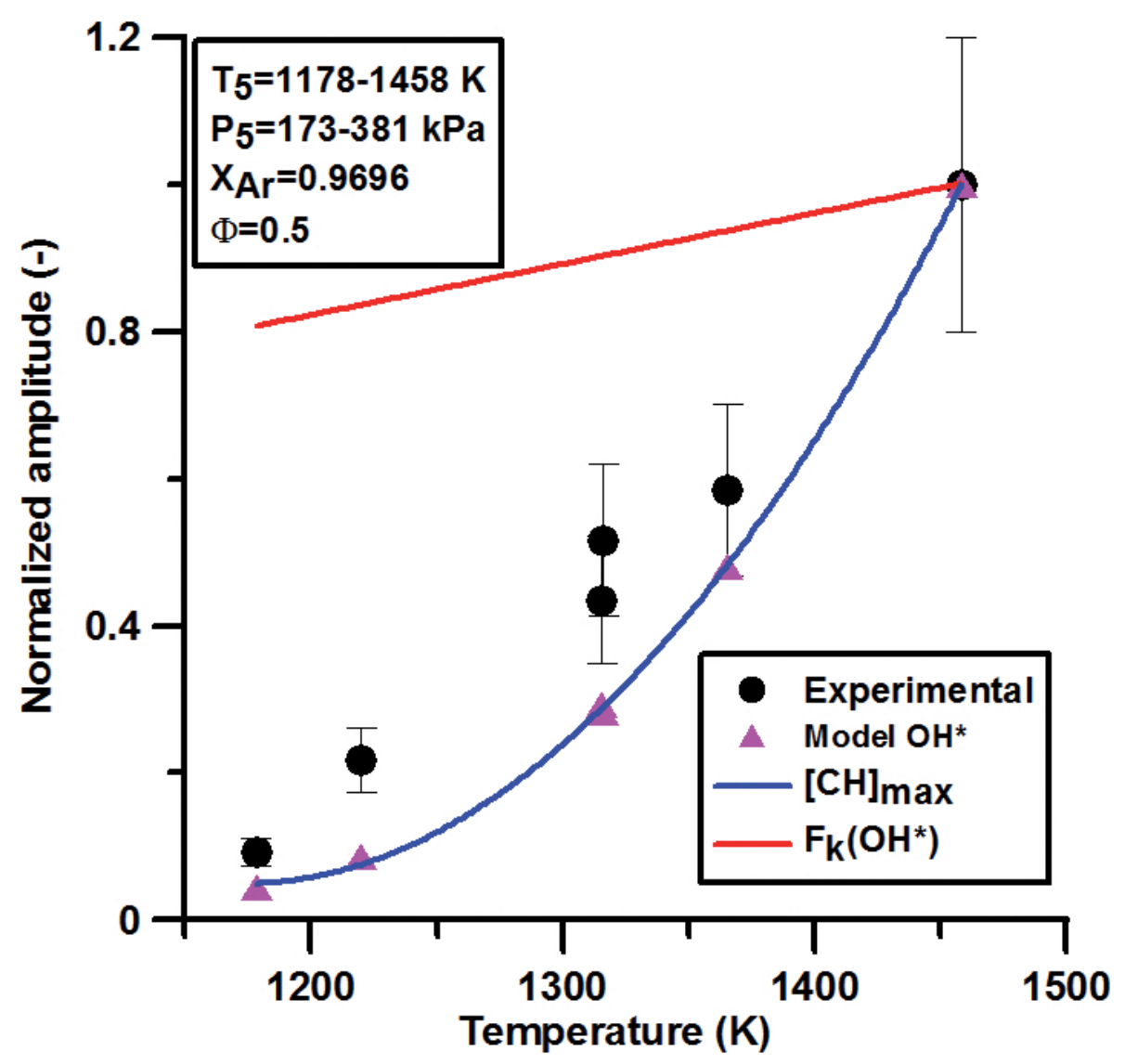

Figure 9: Magnitudes of the normalized values for $F_{k}(O H *),[\mathrm{CH}]_{m a x}$, the experimental emission, and calculated $\mathrm{OH}^{*}$. 


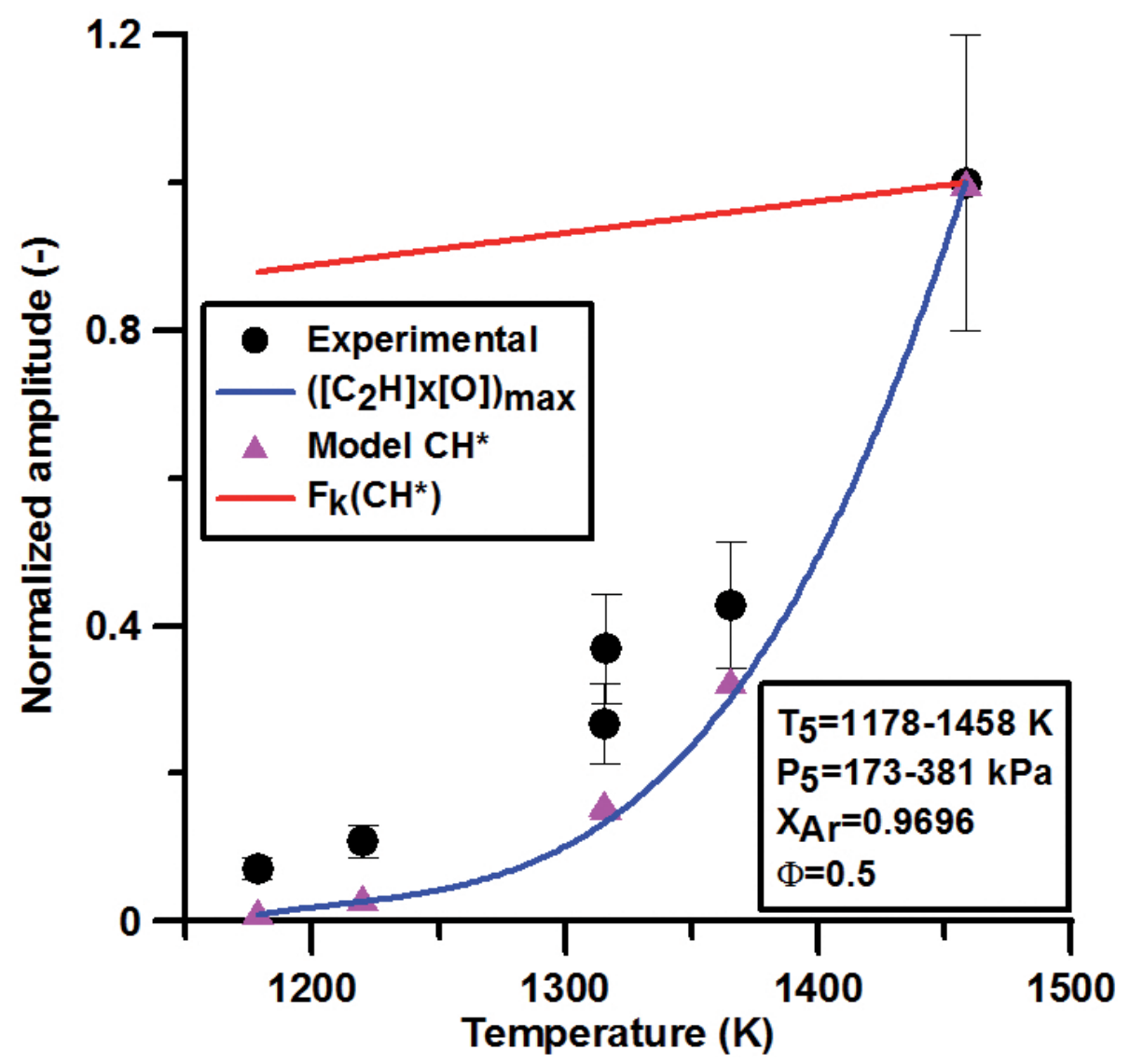

Figure 10: Magnitudes of the normalized values for $F_{k}(O H *),\left(\left[\mathrm{C}_{2} \mathrm{H}\right] \times[\mathrm{O}]\right)_{\max }$, the experimental emission, and calculated $\mathrm{OH}^{*}$. 


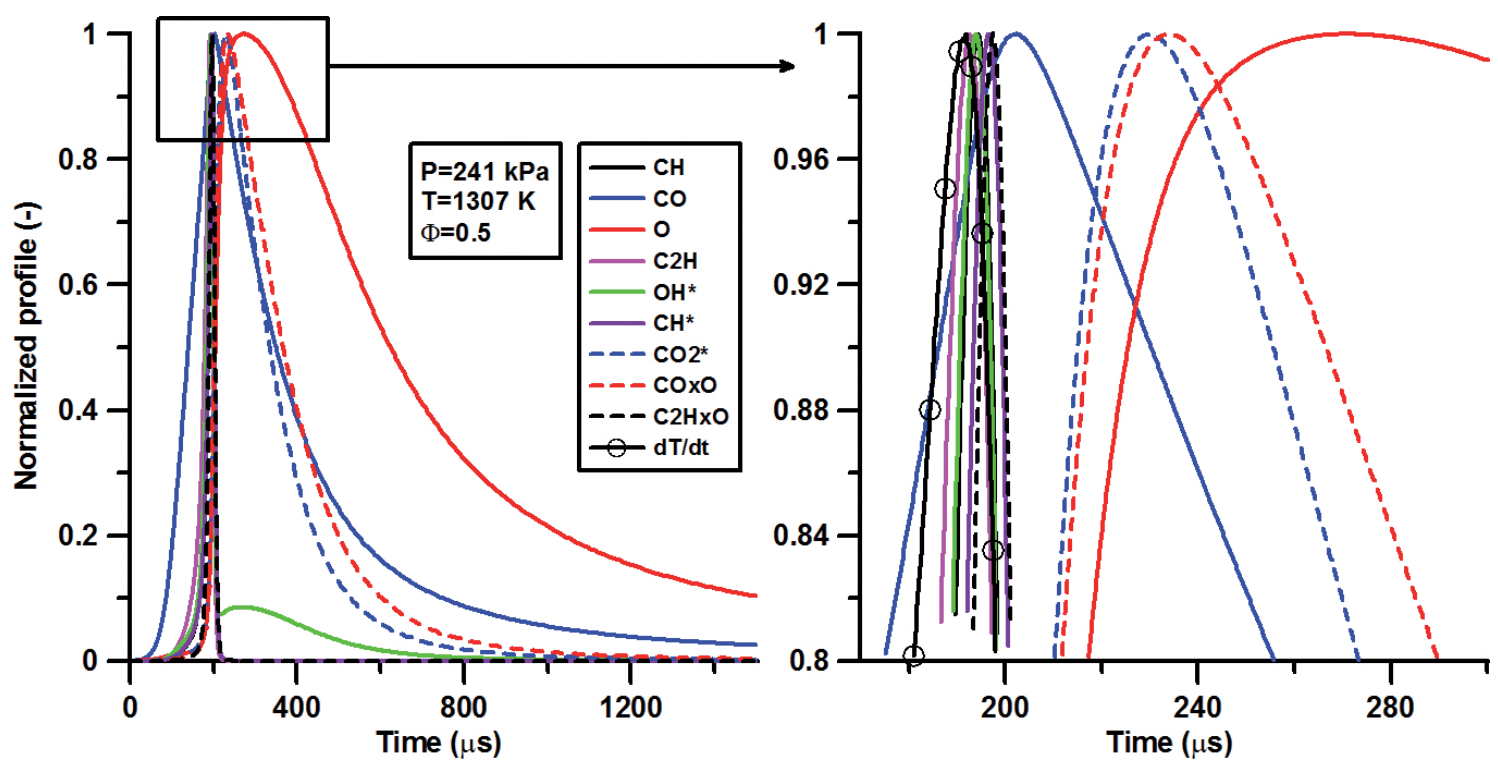

Figure 11: Calculated normalized profiles for excited species and their percursor along with temperature derivative profile. 


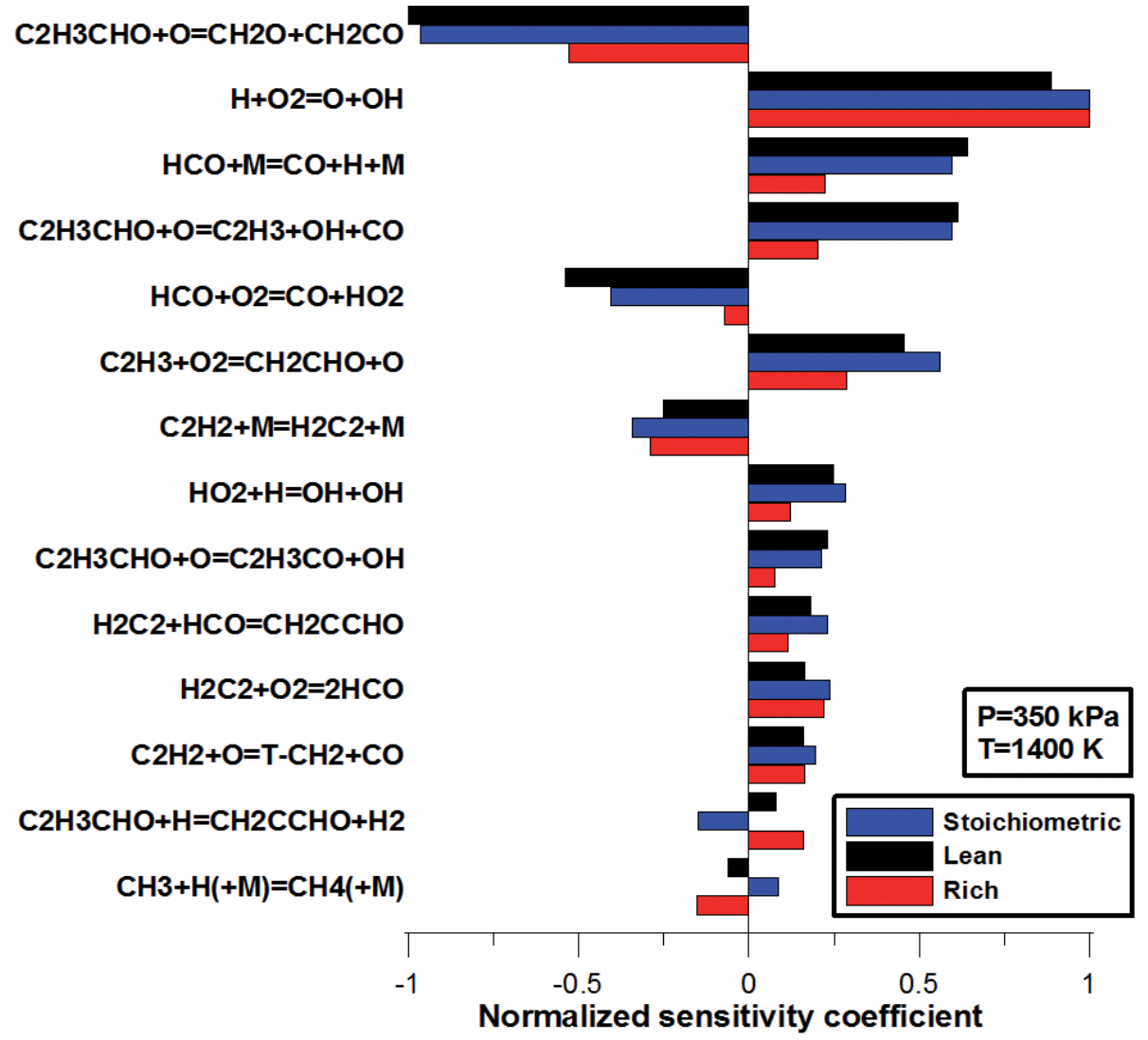

Figure 12: Normalized sensitivity coefficients with respect to temperature for acrolein-oxygen mixtures. 


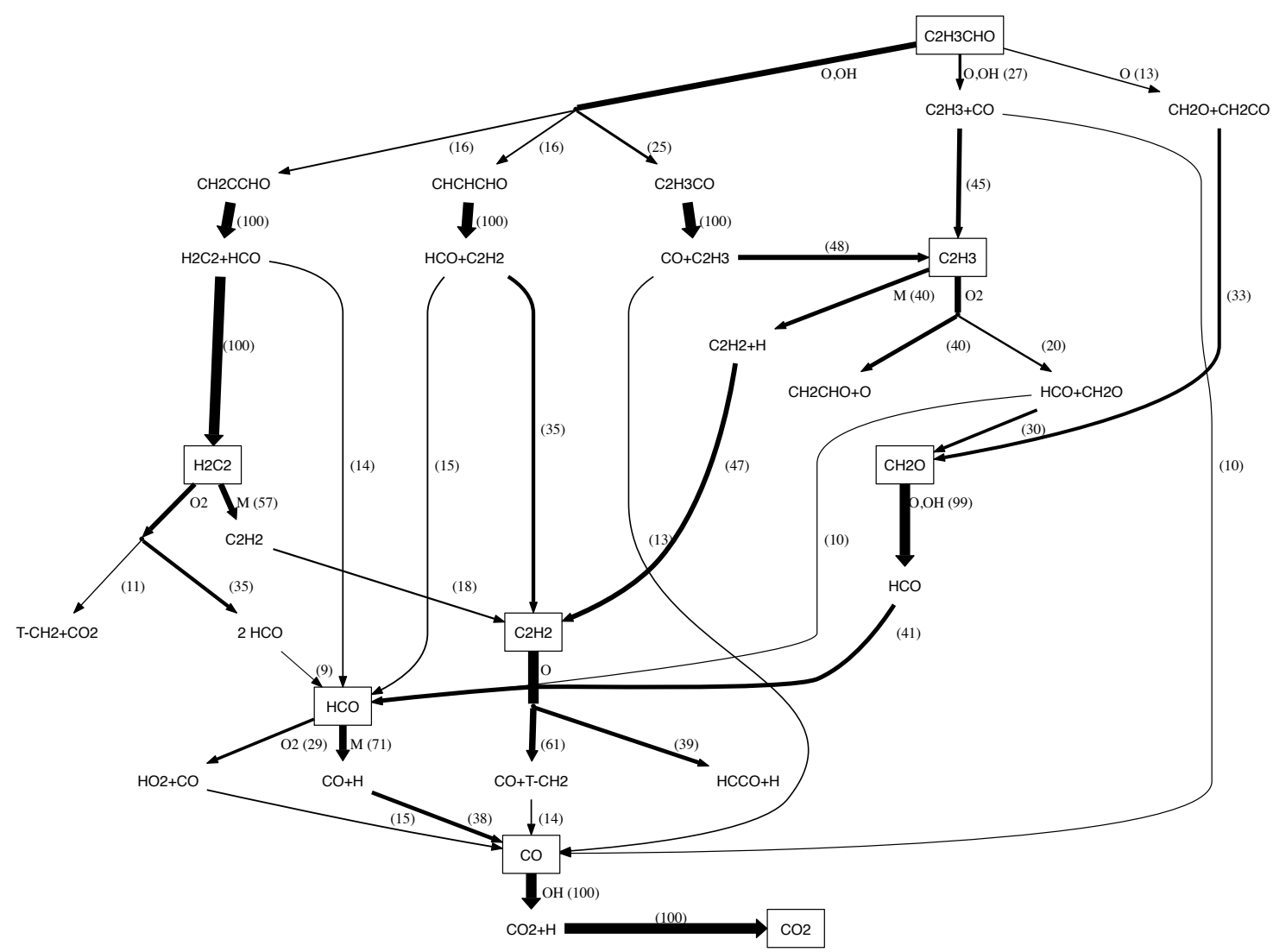

Figure 13: Reaction pathway diagram during the oxidation of a stoichiometric acrolein-oxygenargon mixture. Conditions: $\mathrm{T}=1400 \mathrm{~K} ; \mathrm{P}=350 \mathrm{kPa}$. Frames represent species reservoirs. Arrows thickness is proportional to the relative molar flux (also indicated between brackets). 